\title{
A methodology based on data filtering to identify reference fleets to account for the abundance of fish species: Application to the Striped red mullet (Mullus surmulletus) in the Bay of Biscay
}

\author{
Caill-Milly Nathalie ${ }^{1,{ }^{*}}$, Lissardy Muriel ${ }^{1}$, Bru Noëlle ${ }^{2}$, Dutertre Marie-Adèle ${ }^{3}$, Saguet Cassandre ${ }^{1}$
}

\begin{abstract}
1 Ifremer - Laboratory Environment Resources of Arcachon/Anglet (France), Ifremer - Laboratory Environment Resources of Arcachon/Anglet (France), 1 Allée du Parc Montaury, 64600, Anglet, France 2 CNRS / University of Pau \& Pays de l'Adour/ E2S UPPA, Laboratory of Mathematics and its Applications of Pau - MIRA, UMR5142, 1 Allée du Parc Montaury, 64600, Anglet, France 3 University of Pau \& Pays de l'Adour - STEE College - Montaury Campus, 1 Allée du Parc Montaury, 64600, Anglet, France
\end{abstract}

*Corresponding author : Nathalie Caill-Milly, email address : Nathalie.Caill.Milly@ifremer.fr

\begin{abstract}
:
For data-limited stocks (DLS), professional fishing data can be used as a potential source of information, especially in the absence of appropriate scientific survey, to understand abundance evolution under realistic hypothesis on resource catchability. This work focuses on a data-filtering approach, the selected fishing effort must reflect vessel activity that is least dependent on their technical characteristics and as stable as possible over time. The variable of interest is landing by fishing sequence (landing for a given gear, gear mesh, day and ICES statistical rectangle) called LPUE. In order to account for the abundance of the species, it was necessary to consider the discards. The method thus proceeds in 4 steps: (i) focus on LPUE variability and causes' prioritization; (ii) cluster definition to obtain a typology of vessels; (iii) average LPUE per cluster analysis; (iv) consideration of gear mesh classes and seasonal variations (quarters). This approach is outlined for the Striped red mullet of the Bay of Biscay that is currently in DLS category 5. Two reference fleets are thereby proposed: firstly the otter trawlers composed of small vessels $(7.9-15.8 \mathrm{~m})$ with a gauge of 2-43.9 grt, an engine power between 44 and $256 \mathrm{~kW}$ and a gear mesh of $70-79 \mathrm{~mm}$; secondly the set gillnetters, which are defined by medium-sized vessels $(8.2-14.8 \mathrm{~m}, 2-30.2 \mathrm{grt}, 70-331 \mathrm{~kW}$ ) whose gear mesh is either $50-59 \mathrm{~mm}$ (2nd and 3rd quarters), 60-69 $\mathrm{mm}$ (2nd quarter) or greater than $90 \mathrm{~mm}$ (2nd quarter). LPUEs of these fleets show a downward trend, significant in two out of four cases which may reflect a deterioration of the status of the Striped red mullet stock.
\end{abstract}

\section{Highlights}

- Data-filtering method maximizing usefulness of biological, catch, regulation data. $>$ Fishermen involvement to assess impact of regulation changes on indicators. Potential high bias induced by discards when using LPUE as proxy of abundance. For Striped red mullet, decreasing tendency of LPUEs over the study period.

Keywords : data-limited stock, commercial data, discards, LPUE, professional knowledge, data filtering 


\section{Introduction}

The Common Fisheries Policy (EC 2371/2002), the Johannesburg 2002 World Summit on Sustainable Development, the 1995 United Nations Fish Stocks Agreement and the European plan for moving to maximum sustainable yield (COM (2006) 360 final) are all policy commitments that guide fisheries management decisions in EU waters. For biological resources within European fisheries, stock assessments are thereby required to provide information on the status of stocks in relation to maximum sustainable yield (MSY) objectives. These are established both in terms of stock abundance and fishing mortality rate for each individual stock (Le Quesne et al., 2013). Such targets are achievable for data-rich stocks even if they are not always easily attained. They are a challenge for data-limited stocks (DLS). These stocks lack analytical assessment and are currently the main focus of assessment methods development within the framework of the International Council for the Exploration of the Sea (ICES). The Workshop on the Development of Quantitative Assessment Methodologies (WKLIFE) is a working group which focuses on life-history traits, exploitation characteristics, and other relevant parameters. In the Northeast Atlantic European waters about half of all landings (by weight and value) under exclusive European management are taken from datadeficient unassessed stocks (Le Quesne et al., 2013).

Various reasons can lead to stock being considered as data-limited or data-deficient. This could be because there are uncertainties about the biology of the stock, limited data collection and reporting (lack of or unreliable data on catches, incomplete surveys and/or poor sampling regarding biological parameters, etc.) or limited human resources to develop and apply appropriate assessment models respecting the scientific advisory process (ICES, 2016; Le Quesne et al., 2013). For such stocks, a variety of stock assessment methods and management procedures are available. An important step forward came about in 2012 when ICES implemented the DLS framework to provide quantitative catch advice not only for data-rich stocks but also for data-limited stocks (O'Brien, 2016). Individual stocks are classified among six stock categories defined using available knowledge; categories 2 to 6 
relate to DLS data categories (ICES, 2016, O'Brien, 2013). The category and the management strategies agreed upon by relevant management bodies define the advice rule to be applied on fishing possibilities.

In order to improve assessment and to classify an individual stock into a lower category, catch information is of paramount importance. Especially in the absence of appropriate scientific survey, professional fishing data can be potentially used, under realistic hypothesis on resource catchability, as a source of information to understand abundance evolution. This requires the identification of reference fleets for which catches per unit effort (CPUE) are studied. A source of bias when identifying a derived index of abundance from fisheries rates can come from the available commercial data. The best solution would be to work on catch data (to calculate catch per unit of effort - CPUE) but for many fisheries only landing data (landing per unit effort - LPUE) are available in reality. It is therefore important to understand which factors occur and explain the variability of the commercial catch and landing rates.

Several factors may influence specific rates for a given species: on the one hand, the spatiotemporal characteristics such as year, month and statistical rectangle; on the other hand, technical characteristics of the vessels (primarily length, power, gauge) and characteristics of the gears (more often mesh and length). The former characteristics are more closely related to the biological cycle of the species (migration, concentration, feeding activity influencing availability of resources). The latter characteristics however are more strongly linkedto human activities (fishermen choices or regulation enforcement). In addition, strategy, fishing skill of fishermen, commercial and/or regulatory aspects may also influence spatiotemporal distribution of the catch rates (Hilborn and Walters, 1992). Maunder et al. (2006) provide details on sources of problems when using CPUE data as proxy of abundance.

To investigate those influences and to find a way to reduce them when choosing the fleet of interest and a catch rate, a design-based approach relying on data-filtering (Shearer, 2000) can be 
89

90

91

92

implemented. With regards to potential species, the Striped red mullet is a good candidate for the reasons which we shall set out bellow.

The Striped red mullet (Mullus surmuletus) - also named Surmullet - is a benthic species with a distribution along the European coasts from the Strait of Gibraltar in the south to the south of Norway and north of Scotland including the Faroe Islands (Davis and Edward, 1988; Gibson and Robb, 1997; Quéro and Vayne, 1997). For the North-East Atlantic, areas of management have been identified using otolith shape and their degree of continuity regarding geographic sectors (Benzinou et al., 2013). Individualization of stocks in Western Europe advanced by ICES concerns the Bay of Biscay, the waters bordering the Iberian Peninsula as well as the Celtic Sea, namely for Striped red mullet in Subareas and Divisions 6, 7a-c, e-k, 8, and 9a (and identified by ICES with the following stock code: Mur.27.67a-ce-k89a) - see Figure 1. This stock is part of the DLS, currently classified in category 5 (ICES, 2016); it is a stock for which only landing data are available. The advice rule on fishing possibilities has hence been based on the precautionary approach since 2012. For 2013 and 2014 , ICES recommended reducing landings by $20 \%$ compared to $2009-2011$. In the absence of new information on stock biomass or exploitation level, the precautionary buffer was applied again in 2017 (ICES, 2017). It led to landing advice of a maximum of 1,600 tonnes for 2018, 2019, and 2020. As long as no supporting information clearly indicates that the current level of exploitation is inappropriate for the stock, this approach will be repeated (ICES rules). However, this stock is part of the top 15 landed species by value for South-western waters, a region of Northeast Atlantic European waters (Le Quesne et al., 2013). 


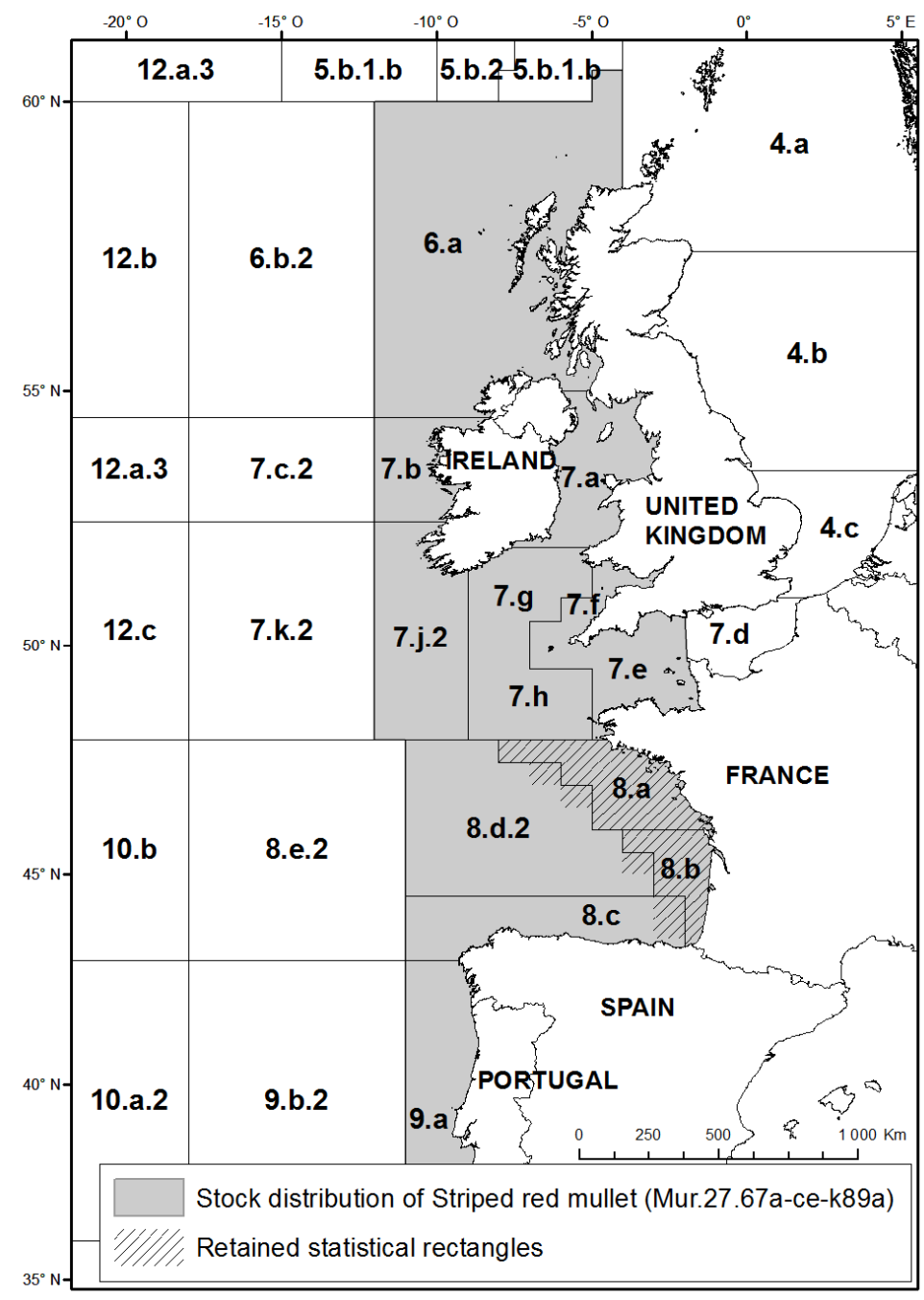

111 Figure 1. Stock distribution of Striped red mullet (Mur.27.67a-ce-k89a) and retained spatial selection

112 for the present study. Sources: ICES, ESRI.

113 The purpose of this study is to propose a data filtering approach to select relevant fleet or fleets

114 whose LPUE can account for abundance. The proposed method consists of four steps and is thus

115 enumerated for Striped red mullet stock in Subareas and Divisions 6, 7a-c, e-k, 8, and 9a. The

116 approach integrates a valorisation of fishermen's expertise thanks to a specialised working group

117 associating scientists and fishermen representatives. 


\section{Material and methods}

\subsection{Identification of potential fleets of interest regarding landings by country and gears}

Landings regarding this stock are primarily taken from ICES Subareas 7 and 8; Subarea 8 being the main contributor. In the last three years, France accounts for two-thirds of landings (ICES, 2017), ahead of Spain, Portugal, UK and the Netherlands. The Surmullet is one species among a set of benthic (demersal) species targeted by the French fleet. Inputs are largely dominated by bottom trawls, gillnets and seines (Danish); these three combinations of gear accounted for $98 \%$ of the landings (for which a gear is specified) over the 2000-2015 period (Caill-Milly et al., 2017). Bottom trawls are basically single-vessel otter trawls and otter twin trawls. Trawls were largely predominant until the mid-2000s. For gillnets, set gillnets (anchored) make up the majority of this category withto a lesser extent- trammel nets. For Danish seines, landings have been recorded from 2008 onwards and, since 2011, these landings have been even higher than those obtained with nets (Appendix A).

According to this landing information, five French fleets are identified as potentially of interest: fleets using otter bottom trawl (OTB); otter twin trawl (OTT); set gillnets (GNS); trammel nets (GTR) and Danish seine (SDN). We must stipulate that only French data will be used in the analysis.

\subsection{Integration of stakeholder knowledge vs scientific knowledge}

From the very beginning of the process analysing how fleets of interest are currently selected, a working group associating professionals (producer organisations, regional and national fisheries committees, Association du Grand Littoral Atlantique) and scientists (Ifremer and University of Pau \& Pays de l'Adour) was set up. Its role was to discuss the available data and their limits, to identify the variability sources of the studied variables and to collectively define the thresholds applied. 


\subsection{Initial data collection, description and quality}

142

143

144

145

146

147

148

149

150

151

152

153

154

155

156

157

158

159

160

161

Data on catches by commercial fishing fall under two categories: landing and discards data. For these data, the statistical units are the fishing sequences for each vessel. These fishing sequences are defined by the combination of the day, the gear, the gear mesh size and the statistical rectangle. Landing data are validated, consolidated and qualified sets of production and effort data provided by a cross validation algorithm (named SACROIS) for fisheries statistics (Demanèche et al., 2013; http://sih.ifremer.fr/Description-des-donnees/Les-donnees-estimees/SACROIS). This tool meets the EU requirement stipulated by article 145 of the EU implementing regulation (EC Reg. 404/2011). SACROIS data are considered as the most comprehensive for reporting French vessel activity and their inputs (landings). They have been available since 2000 and were extracted over the 2000-2015 period. For Surmullet, it represents 1,179,531 fishing sequences. Each line contains the amount of Surmullet landing per fishing sequence and per vessel. It constitutes therefore a quantification of landing per unit effort (LPUE).

Discards data originate from the "Observation on board fishing vessels" programme (hereby referred to as the OBSMER French programme; Cornou et al., 2015). It is a collection of on-board catch data; they are therefore sampling data whereas SACROIS data are considered as exhaustive. This national programme enables observation at sea in the fishing areas of the part kept to be sold (landings) and the part not retained on board (discards) as well as the gears used in situ. Therefore, for each fishing operation, we have information about catches landed and discarded, fishing activity and effort. OBSMER data have been available since 2003 and were extracted for the 2003 - 2015 period. For Surmullet, it represents 14,950 fishing sequences.

Regarding vessels, their technical characteristics may change over time due to transformations (such as remotorization, fishing gear shifts, etc.). To have the most precise information throughout the boats' life cycle, annual characteristics were collected from the Community Fishing Fleet Register (http://ec.europa.eu/fisheries/fleet/index.cfm). 


\subsection{Data preparation}

167

168

169

170

171

172

173

174

175

176

177

178

179

180

181

182

\subsubsection{Data selection according to vessel activity, areas and time}

The study population was defined by activity criteria applied to the vessels and by the spatial extent of the inputs.

We considered that a vessel had to be selected if its activity was equivalent to the mean of two fishing trips per month, per year (all gears combined) with the presence of Striped red mullet (initially regardless of the distribution of these fishing trips during the year).

Two criteria were applied concerning the spatial extent of the inputs. The first one is related to vessel strategies. Within the geographical area defined for the Mur.27.67a-ce-k89a stock, vessels from harbours of the Bay of Biscay and those coming from outside of the bay and catching Surmullet develop different fishing strategies (Caill-Milly et al., 2017). To overcome a bias in the calculation of the LPUE that would be related to these differences, we focused the analysis on the main input area that presents consistent techniques, namely the divisions "27.8.a", "27.8.b", "27.8.c", "27.8.d", and "27.8.e". The second criterion refers to the studied species biology. We retained the statistical ICES rectangles $\left(0.5^{\circ}\right.$ latitude and $1^{\circ}$ longitude) consistent with the bathymetric distribution of Surmullet that is less than or equal to 300 m (Suquet and Person-Le Ruyet, 2001; Mahé et al., 2005) (see Figure 1 presented before).

Moreover, regulatory changes may affect the indicators of catches and/or landings per unit of effort (CPUE and/or LPUE). It is therefore important to identify them and limit their effects. For the Surmullet, a preliminary graphical analysis of landings by fishing trip and statistical rectangle between 2000 and 2015 showed clear trend changes in 2005 for both trawlers and netters (Appendix B). Discussions held by the working group of the project allowed this observation to be linked to the implementation of a selectivity device, later confirmed by the Council Regulation (EC) No. $1288 / 2009$. To overcome this regulatory bias, we limited the various analyses to the $2005-2015$ 
period. Error! Reference source not found. displays the mean annual landings per statistical rectangle in the retained area (2005-2015 period; all fishing gears); Table 1 displays the mean characteristics of the retained vessels for the analysis.

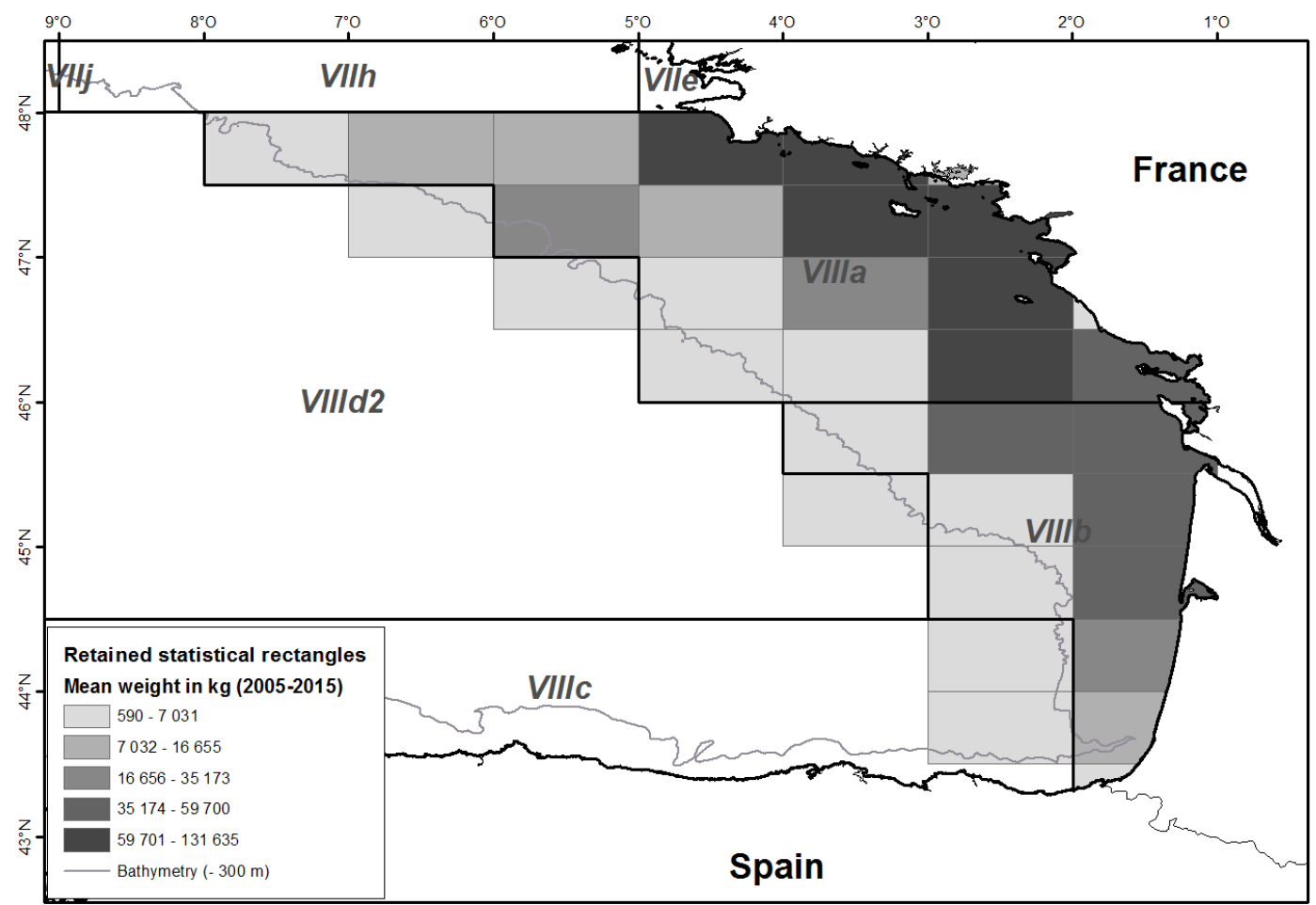

Figure 2. Mean annual landings per retained statistical rectangle (2005-2015 period; all fishing gears). Sources: ICES, ESRI, Sacrois data V3.3.5.

\begin{tabular}{|l|c|c|c|c|c|}
\hline \multicolumn{1}{|c|}{ Group of gears } & $\begin{array}{c}\text { Number of } \\
\text { vessels }\end{array}$ & Length $(\mathrm{m})$ & Gauge (tjb) & $\begin{array}{c}\text { Engine } \\
\text { power }(\mathrm{kW})\end{array}$ & $\begin{array}{c}\text { Years of } \\
\text { service }\end{array}$ \\
\hline Otter trawls (OTB) & $249(47)$ & $14.4(4.3)$ & $44.6(44.7)$ & $223(123.7)$ & $30(10)$ \\
\hline $\begin{array}{l}\text { Otter twin trawls } \\
\text { (OTT) }\end{array}$ & $200(40)$ & $16.7(3.7)$ & $67.7(43.6)$ & $289.6(103)$ & $29(9)$ \\
\hline Set gillnets (GNS) & $136(26)$ & $10.4(3.7)$ & $18.4(33.7)$ & $125.2(91)$ & $31(10)$ \\
\hline Trammel nets (GTR) & $128(23)$ & $11.9(4.2)$ & $29(41.5)$ & $156.1(101)$ & $31(10)$ \\
\hline Danish seines (SDN) & $8(5)$ & $24.3(5.9)$ & $169.4(70.9)$ & $479.8(89.7)$ & $20(11)$ \\
\hline
\end{tabular}

195 Table 1. Characteristics by gear of vessels having landed Surmullet (2005-2015 period). 
2.4.2 Data cleaning process, calculations on aggregations and impact assessment of discards

The "cleaning" process concerned only the landing data. Three concepts for defining unappropriated data were identified: outliers pinpointed by expert opinions, data corresponding to vessels with fishing time equal to zero or not filled in and unavailable data regarding statistical rectangles.

Level indicators (mean, median) and dispersal indicators (interquartile range IQR, variance Var, standard deviation StD, and coefficient of variation CV) of the LPUE were calculated and displayed in columns using the following aggregation: year, month, rectangle, vessel registration, vessel length, vessel power, vessel tonnage, gear and gear mesh size (grouped in mesh class). Each information per individual vessel are conserved in this way. For discards, the calculated column parameters are the mean, the median and the standard deviation of the catches and the discards. The aggregation used was: year, month, rectangle and gear. For the latter, the level of aggregation is not as precise because it is based on a limited number of observations related to sampling. In addition, the total number of fishing sequences and the number of sequences only with Surmullet were also added, as well as the total weight of the fishing trip and added to the dataset in columns.

In our case study, the amount of Surmullet landing per fishing sequence and per vessel is potentially considered as a proxy of relative abundance. It is therefore essential to ensure, in advance, that the discards do not affect the variables studied. An analysis was thus conducted for each of the five identified French fleets (OTB, OTT, GNS, GTR and SDN) to evaluate the discards proportion and their characteristics. Different criteria were analysed simultaneously: the availability of a sufficient number of observations, the proportion of discards mean by month and by year from the number of total sequences carried out, the stability of this level over time and the size composition of the discards (N.B. there is no minimum catch size for Surmullet but a minimal commercial landing weight at 40 grams (EC Regulation No. 2406/96) that amounts to a total length of around $18 \mathrm{~cm}$ ). This preliminary work allows us to retain the gears that could be used to define the reference fleets. 


\subsection{Analytical process of landing data to select a representative fleet}

222 The objectives of the study is to identify a derived index of abundance from fisheries rates. To select

223 the fleet(s) of interest, the approach deployed consist of a four-step based data exploration using

224 data mining tools and visualization techniques. This approach is applied to each of the potential fleets of interest (OTB, OTT, GNS, GTR and SDN).

\subsubsection{Step 1: identification of the factors influencing LPUE level and dispersion}

This first step focused on evaluating the different sources of variability of the LPUEs. It is based on the analysis of links between the variables of interest characterizing the LPUEs, the vessel characteristics and activity (length, gauge, engine power, gear mesh class), and the spatiotemporal factors (year, month, statistical rectangle). It is also a question of prioritizing each effect. Two statistical approaches were conducted on the same dataset. The first approach looked for linear links using a normalized principal components analysis (NPCA) (see Error! Reference source not found. for parametrization details) completed by the assessment of the discriminating power of each variable (Kruskal-Wallis test on the first component of the NPCA). The second one looked for other links (nonlinear) and investigated possible interactions between explanatory variables using conditional regression trees. This analysis enables rules to be found, thereby giving the values of a target variable (here the log-transformed LPUE) from a set of explanatory variables (the previous active variables used for NPCA - see Error! Reference source not found.). The obtained rules can be displayed graphically using a binary tree (De'ath and Fabricius, 2000). The branches of the tree diagram are determined by the splitting rules (maximization of the homogeneity of the two resulting groups with respect to the response variable) (Prasad et al., 2006). Each node characterised a relevant variable allowing the value of this response variable to be divided. For each one, the mean response, the 


\begin{tabular}{|c|c|c|c|}
\hline Type & Variables & Status & Abbreviation \\
\hline \multirow{2}{*}{$\begin{array}{l}\text { Level indicators } \\
\text { of LPUE* }\end{array}$} & Mean & \multirow[t]{15}{*}{ Active } & Moy \\
\hline & Median & & Med \\
\hline \multirow{4}{*}{$\begin{array}{l}\text { Dispersal } \\
\text { indicators of } \\
\text { LPUE* }^{*}\end{array}$} & Variance & & Var \\
\hline & Standard deviation & & StD \\
\hline & Interquartile range & & IQR \\
\hline & Coefficient of variation & & $\mathrm{CV}$ \\
\hline \multirow{5}{*}{$\begin{array}{l}\text { Technical } \\
\text { characteristics of } \\
\text { vessels and gears }\end{array}$} & Length & & Loa \\
\hline & Gauge & & Ton_Ref \\
\hline & Engine power & & Power_Main \\
\hline & Gear mesh & & Maillage \\
\hline & Gear mesh class & & Classes \\
\hline \multirow{2}{*}{$\begin{array}{l}\text { Landing } \\
\text { characteristics }\end{array}$} & Surmullet weight & & Pds_MUR \\
\hline & Total weight & & Pds_Tot \\
\hline \multirow[t]{2}{*}{ Fishing sequences } & Number of sequences with Surmullet & & Nb_SqP_MUR \\
\hline & Total number of sequences & & Nb_SqP_Tot \\
\hline \multirow[t]{2}{*}{ Time } & Month & \multirow{3}{*}{$\begin{array}{l}\text { Supple- } \\
\text { mentary }\end{array}$} & Mois \\
\hline & Year & & Année \\
\hline Space & Statistical rectangles & & Rectangle \\
\hline
\end{tabular}

247 Table 2. Variables used to parametrize the NPCA.

\subsubsection{Step 2: focus on those involved, vessel typology according to technical} characteristics

The objective of this step was to perform a vessel typology with the most homogeneous technical

253 (HAC with Ward aggregation criterion and Euclidean distance). The number of clusters was chosen

254 arbitrarily according to the visual cut of the dendrogram while avoiding too low numbers of vessels 
2.5.3 Step 3: selection of the most meaningful cluster using a multicriteria approach

\begin{tabular}{|c|c|c|c|}
\hline Type & Characteristics & Condition & Why? \\
\hline \multirow{3}{*}{ 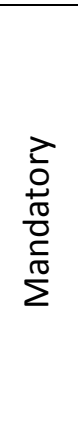 } & Number of vessels & $>30$ & $\begin{array}{l}\text { To have sufficient statistical units for } \\
\text { classical statistical inferences }\end{array}$ \\
\hline & $\begin{array}{l}\text { Length of the } \\
\text { LPUEs time series } \\
\text { in the Bay of Biscay }\end{array}$ & $>11$ years & $\begin{array}{l}\text { Greater than the maximum longevity } \\
\text { known for Striped red mullet (ICES, } \\
\text { 2012; Quéro and Vayne, 1997) }\end{array}$ \\
\hline & $\begin{array}{l}\text { Minimum level of } \\
\text { LPUE }\end{array}$ & $>5 \mathrm{~kg}$ & $\begin{array}{l}\text { It was considered that the monthly } \\
\text { mean value of the LPUE must be at } \\
\text { least the median value of the LPUEs }\end{array}$ \\
\hline \multirow{2}{*}{$\begin{array}{l}\overline{\frac{\pi}{0}} \\
\frac{0}{0} \\
\frac{0}{2}\end{array}$} & $\begin{array}{l}\text { Seasonal signal of } \\
\text { the LPUEs }\end{array}$ & $\begin{array}{l}\text { Amplitude with weak interannual } \\
\text { variability } \\
\text { Moderate variability of the periodicity }\end{array}$ & $\begin{array}{l}\text { To be representative of the biological } \\
\text { signal of abundance }\end{array}$ \\
\hline & $\begin{array}{l}\text { Spatial availability } \\
\text { of the LPUEs }\end{array}$ & $\begin{array}{l}\text { Activity available in the North and in } \\
\text { the South of the Bay of Biscay }\end{array}$ & $\begin{array}{l}\text { To consider as much as possible the } \\
\text { entire range of Surmullet in this area }\end{array}$ \\
\hline
\end{tabular}

A list of mandatory and optional conditions was established to identify the relevance of each cluster according to expert advice (Table 3) as we commonly do in operational research for decision-making support. The mandatory criteria referred to the possibility of undertaking statistical inferences, having a time series length consistent with the species' biology and selecting vessels displaying a sufficient LPUE. Fulfilling those conditions was necessary but not sufficient, that is why we added optional criteria which concern biological aspects (spatial and seasonal).

Table 3. Mandatory and optional conditions.

Optional criteria are not quantitative. Therefore to facilitate the selection process, a points system was applied using three-levels coding: 1 - lack of correspondence to the criteria, 2 - medium correspondence, 3 - strong correspondence. The sum of all the scores provided the final unique index according to the entire optional criteria. Based upon the review of average LPUEs per cluster (in the entire, in the north and in the south of the Bay of Biscay), the notations were proposed by the scientists and subsequently validated during the working group associating the professionals. 
272 Applying these conditions to the clusters obtained in $\S 2.5 .2$ allows us to preselect or not, one or

273 more potential candidate clusters to be the reference fleet for each of the gears. The whole process is presented in Figure 3. 2000).

\subsubsection{Step 4: final refinement of the reference fleet and temporal window to consider LPUEs as proxy of abundance}

To refine the selection process, the representativeness of the gear meshes characteristics was computed for each selected cluster and the following criteria were considered: the representativeness of the landing levels of the whole cluster, continuity of use and a sufficient number of uses. One or more cluster/gear mesh class combinations were thus retained. To identify possible more relevant periods to reflect abundance, the monthly means of LPUEs over the 2005 to 2015 period for each combination were computed associated with their corresponding confidence intervals. If a clear fishing period was identified (and confirmed during the working group associating fishermen), only the LPUEs data for this period were selected. This filtering over the fishing season avoids a bias related to the seasonal variability of the fishery (Laurec and Le Gall, 1975 in Girard et al., 


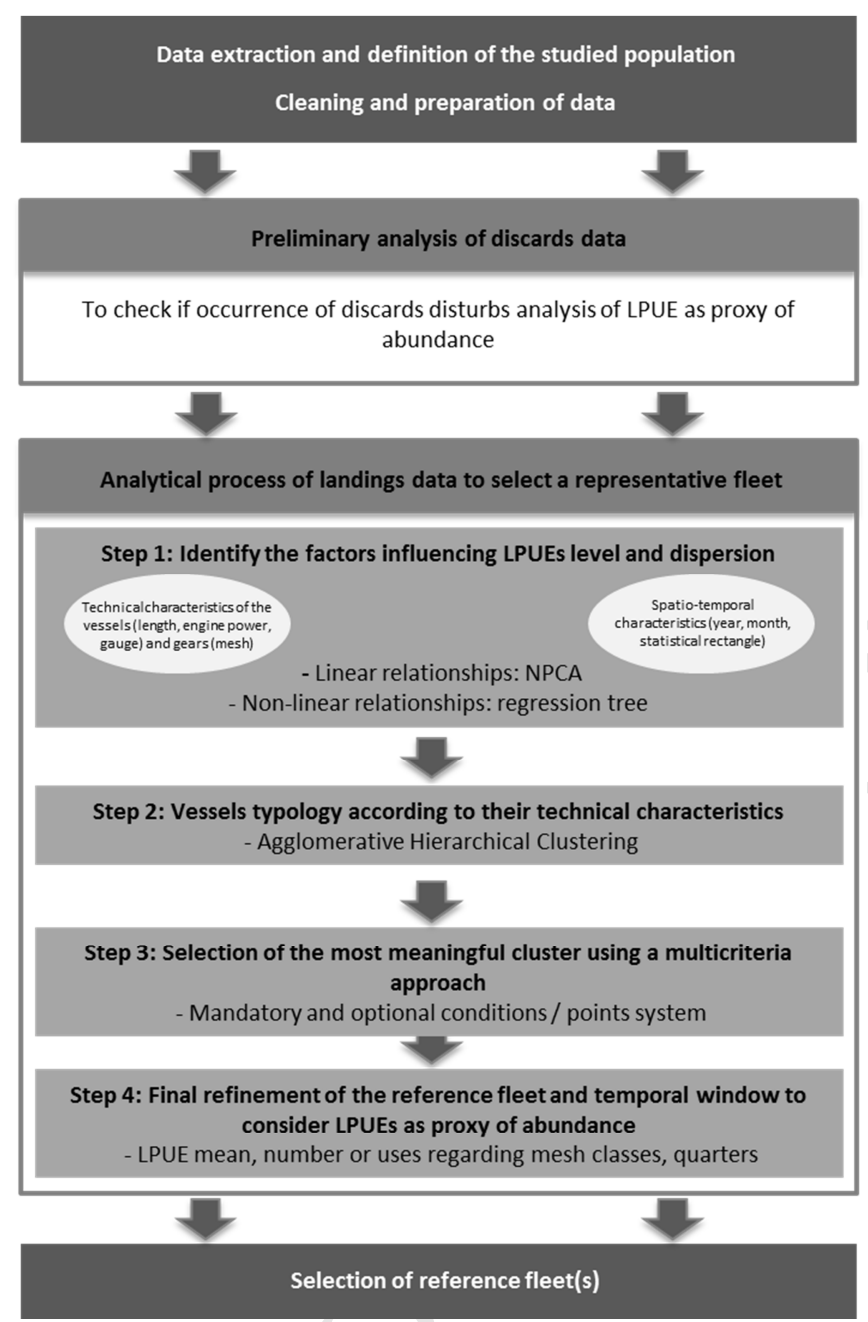

Figure 3. Retained approach for the identification of reference fleets from the LPUE study.

289 For the identified fleets, the trend of the monthly LPUEs is considered as reflecting changes in

290 Surmullet abundance and the slope of the regression line is tested. Calculations were carried out under R Software, using the packages: "FactoMineR" for the NPCA and HAC, "rpart" for the regression trees.

\section{Results}

\subsection{Preliminary study to evaluate discards impacts}

For the five selected gears a priori (OTB, OTT, GNS, GTR and SDN), we have enough discards data to decide on the importance of them (Appendix C). The Danish seines time series sea observations 
trawlers and set gillnets the numbers of observations and their position within the year are significant. However, the distribution of the OBSMER data along the 2003-2015 period reveals better coverage of the fishing activity since 2009. This change corresponds to the decision taken by the Ministry of Agriculture and Fisheries to intensify the observations aboard ships. Consequently, the analysis is truncated to the 2009-2015 period for the four remaining gears (Appendix D). Otter bottom trawls (OTB), Otter twin trawls (OTT) and Set gillnets (GNS) show low discards of fishes above the commercial weight (essentially less than $3 \%$ on average for OTB; less than $1 \%$ for OTT; less than $5 \%$ for GNS). Regarding Trammel nets (GTR), the discard rates are regularly higher than $15 \%$ (whether per year or per month). For trawlers, the phenomenon seems stationary over the period (except in December when this rate reaches $11 \%$ for OTB). For gillnetters, the monthly average is characterized by higher values for January and November. GTR shows a peak in March $(40 \%$ on average).

The analytical process of analysing landing data was therefore applied to OTB, OTT and GNS. For OTT, a mandatory condition was not fulfilled (Step 4 - LPUEs below the set threshold value from 2012 onwards). Consequently, only results for OTB and GNS are presented (detailed for OTB, less detailed for GNS). They potentially allow us to propose LPUEs as abundance proxy, but only for fishes above the commercial weight - $40 \mathrm{gr}$.

\subsection{Results for otter bottom trawls (OTB)}

\subsubsection{Step 1: identify the factors influencing LPUE}

The sum of the two dimensions of the NPCA is equal to $81 \%$, thus clearly accounting for the variability of the LPUEs and their associated indicators of level and dispersion. However, it does not highlight linear relationships between the LPUE levels, their variability indicators and the technical characteristics of the vessels (Figure 4). Dim1 combines most of the indicators of level and dispersion revealing correlation between level characteristics of LPUE and dispersion ones: the variance is high 
322 if the level of LPUE is high. This dimension shows a size effect and to characterize it, the Kruskal-

323 Wallis test confirms that statistical rectangle, month, year and gear mesh classes are significant

324 discriminant variables.

325

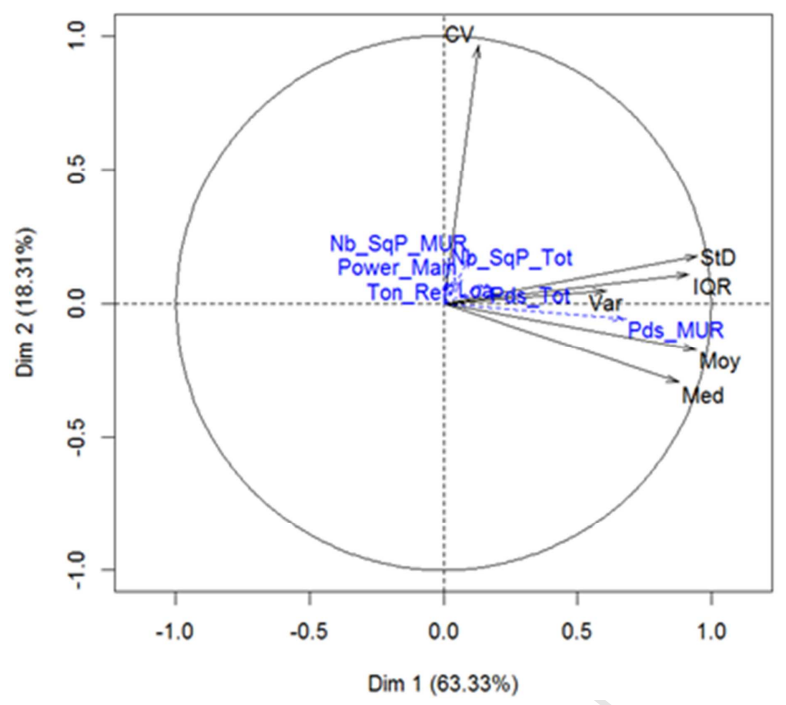

326 Figure 4. Correlation circle for OTB using the first two dimensions.

327 In order to evaluate the effect of technical characteristics to account for LPUE levels, a conditional regression tree was used, considering values of log10moy to be explained and technical characteristics as input variables (Figure 5). The highest LPUEs (bold values in the table in Error!

Reference source not found.) are associated with vessels of which:

- Rule 1: the engine power is greater than $405 \mathrm{~kW}$ when associated with a gear whose mesh is less than $79 \mathrm{~mm}$;

- Rule 2: the engine power is between 129 and $405 \mathrm{~kW}$, and gear has a mesh less than $70 \mathrm{~mm}$;

- Rule 3: the vessel length is less than or equal to $11.95 \mathrm{~m}$ and the gear associated with a gear mesh equal to or less than $80 \mathrm{~mm}$. 


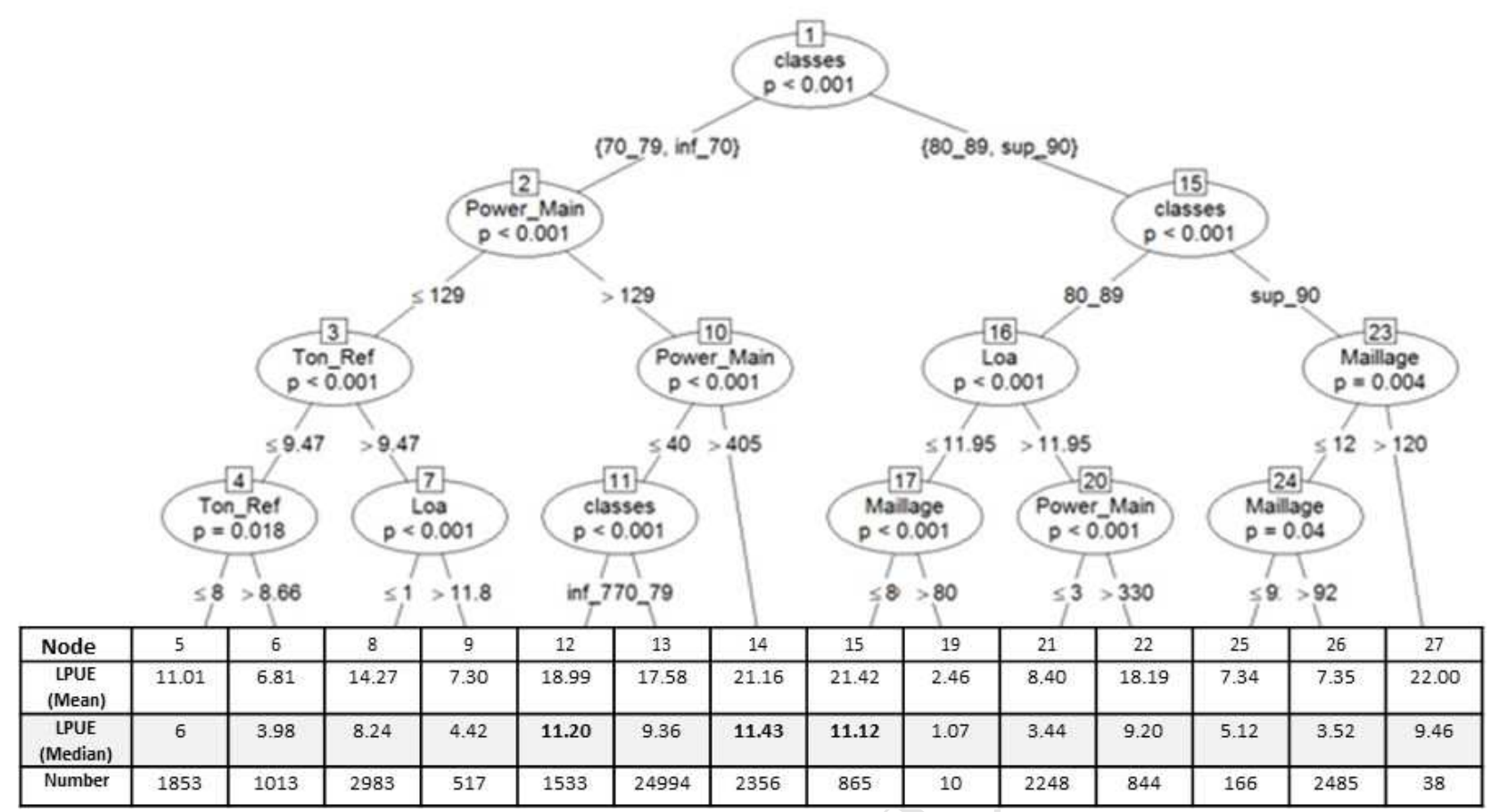

Figure 5. Conditional regression tree on log10Moy (standardized LPUE) with technical characteristics (the values in columns correspond to the values of each node).

\subsubsection{Step 2: vessel typology}

Implementation of HAC on the technical characteristics of the vessels allows for three distinct clusters to be distinguished (characteristics displayed in Table 4). Small vessels (between 7.9 and 15.8 $\mathrm{m}$ ) with a small gauge between 2 and $43.9 \mathrm{grt}$, and an engine power between 44 and $256 \mathrm{~kW}$ define cluster 1 . Cluster 2 is composed of large vessels (between 16.5 and $37.2 \mathrm{~m}$ ), with a gauge between 58 and $361 \mathrm{grt}$ and an engine power between 261 and $1080 \mathrm{~kW}$. Cluster 3 is characterized by mediumsized vessels (between 14.1 and $20.3 \mathrm{~m}$ ), with a gauge between 29.5 and 115.8 grt and an engine power between 200 and $351 \mathrm{~kW}$.

\begin{tabular}{|c|c|c|c|c|c|c|c|c|c|c|c|}
\hline \multicolumn{3}{|c|}{ Cluster } & \multicolumn{4}{c|}{ Vessel length $(\mathbf{m})$} & \multicolumn{4}{c|}{ Gauge (grt) } & \multicolumn{3}{c|}{ Engine power (kW) } \\
\hline Code & Number & Min & Mean & Max & Min & Mean & Max & Min & Mean & Max \\
\hline 1 & 299 & 7.9 & 11.3 & 15.8 & 2 & 15.9 & 43.9 & 44 & 140.9 & 256 \\
\hline 2 & 151 & 16.5 & 21.0 & 37.2 & 58 & 114.5 & 361 & 261 & 398.7 & 1080 \\
\hline 3 & 138 & 14.1 & 15.9 & 20.3 & 29.5 & 48.6 & 115.8 & 200 & 275.4 & 351 \\
\hline Total & 588 & & & & & & & & & \\
\hline
\end{tabular}




\subsubsection{Step 3: cluster selection}

For each cluster, changes in landing average calculated by month and by year are shown in Figure 6 .

Cluster 2 presents a high variability at the end of the period. For clusters 1 and cluster 3 , the variability decreases during the studied period as well as the average landings of Surmullet. At the end of the period, cluster 1 displays low variability and low average landings. Conversely, cluster 3, which has a higher landing average, maintains some cyclicality in the levels of the LPUEs.

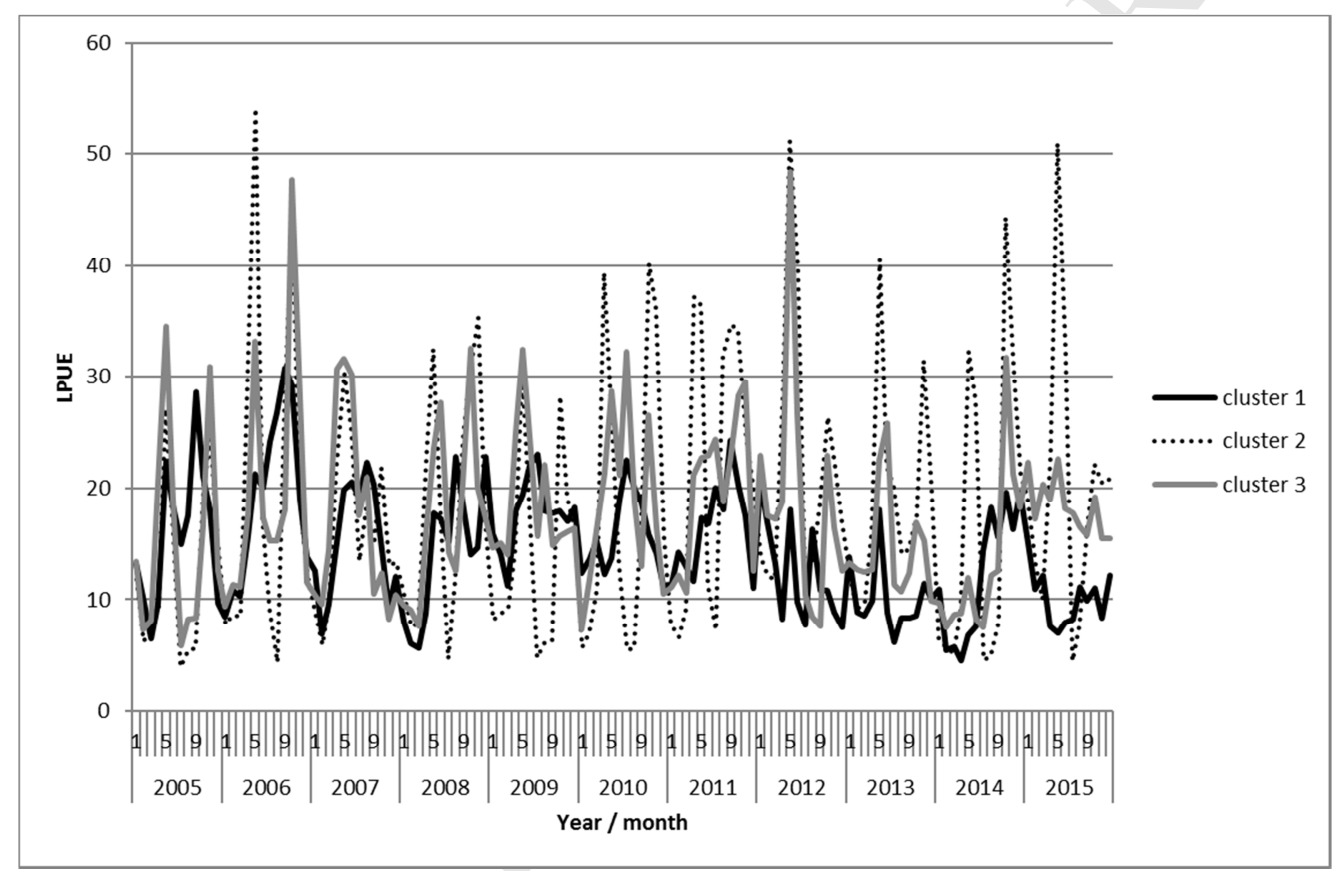

Figure 6. Average LPUEs per cluster for Surmullet in the Bay of Biscay.

To consider spatial availability of the LPUEs, the optional multi-criteria selection method focuses on what happens in the north and in the south of the Bay of Biscay (see Appendix E). The activity of the three clusters are present in both areas even if it is less true for cluster 2 . Clusters 2 and 3 show high variability on average with an increase in the north for cluster 2 and a decrease in the south for cluster 3 at the end of the period. Cluster 1 is characterized by a slightly decreasing variability over time. 
Considering Figure 6 and Appendix E, all mandatory criteria are completed for the 3 OTB clusters.

Table 5 summarizes the results following the application of the optional conditions on the data

series. Although the results are close, this point system allows us to propose cluster 1 for OTB.

364

\begin{tabular}{|c|l|c|c|c|}
\hline \multicolumn{2}{|c|}{ Multi-criteria selection method } & \multicolumn{3}{c|}{ Gear: OTB } \\
\hline Level of obligation & Vessel typology (technical characteristics) & Cluster 1 & Cluster 2 & Cluster 3 \\
\hline \multirow{4}{*}{ Optional } & $\begin{array}{l}\text { Stable seasonal signal (both in amplitude and periodicity) } \\
\text { during the series }\end{array}$ & $1 / 3$ & $1 / 3$ & $1 / 3$ \\
\cline { 2 - 5 } & Activity present in N and S of the Bay of Biscay & $3 / 3$ & $2 / 3$ & $3 / 3$ \\
\cline { 2 - 5 } & Moderate seasonal variability & $3 / 3$ & $2 / 3$ & $2 / 3$ \\
\hline \multicolumn{2}{|c|}{ Notation } & $7 / 9$ & $5 / 9$ & $6 / 9$ \\
\hline \multicolumn{2}{|c|}{ Proposed ranking } & 1 & 3 & 2 \\
\hline
\end{tabular}

365 Table 5. Classification of clusters for OTB.

\subsubsection{Step 4: final refinement of the reference fleet}

The monthly evolution of the LPUEs for each of the gear mesh classes used for cluster 1 - OTB is shown in appendix F. The 70-79 $\mathrm{mm}$ mesh class is by far the most represented class for this cluster at around $85 \%$. We therefore focus, henceforth, on the LPUE cluster 1 - OTB - mesh 70-79 mm. For this gear mesh size of interest, the average LPUEs oscillate between 10 and $20 \mathrm{~kg}$ per unit of effort according to the month. They are the strongest between May and October (Figure 7).

372

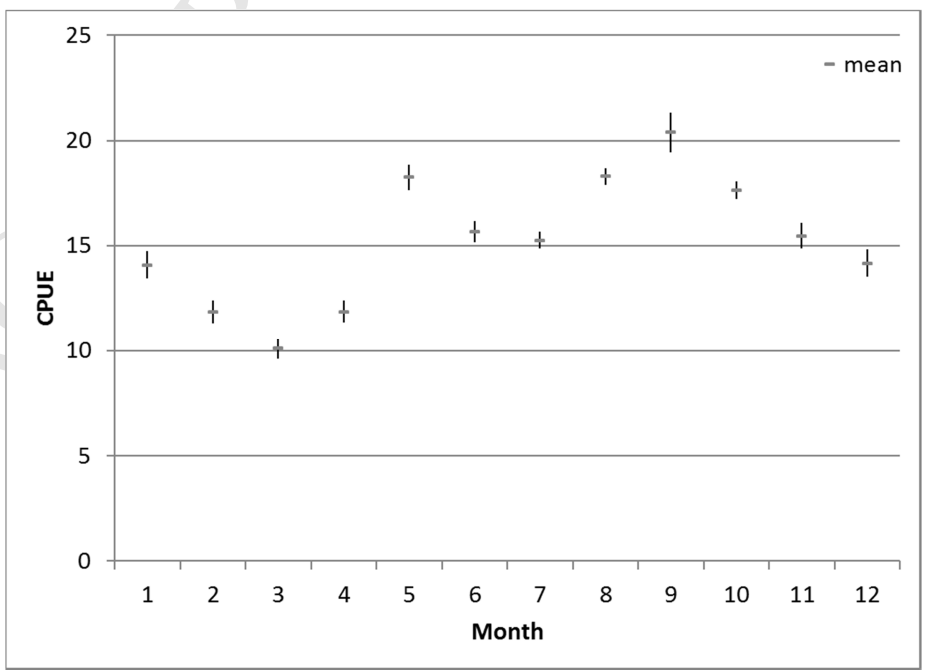

Figure 7. Average LPUEs per month over the 2005 to 2015 period for cluster 1 - OTB - 70 - $79 \mathrm{~mm}$. 


\section{ACCEPTED MANUSCRIPT}

Based on these characteristics, working throughout the year on this fleet is proposed. For cluster 1 OTB with a $70-79 \mathrm{~mm}$ gear mesh size, the evolution of its use over time and of the LPUEs for the whole Bay of Biscay are considered. The number of uses of the mesh $70-79 \mathrm{~mm}$ for OTB cluster 1 shows a slight decrease during the study period; however, this decrease is not significant. LPUE also decreases over the period of study but significantly so in this case (Figure 8).
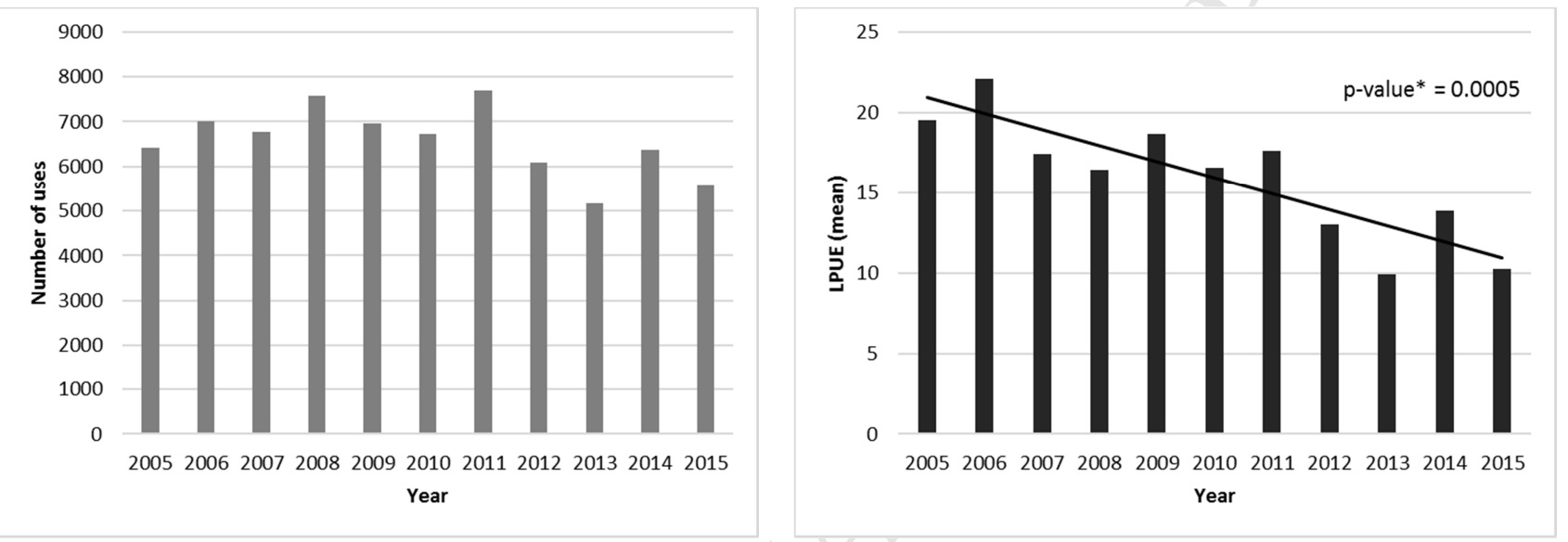

Figure 8. Number of uses and levels of associated LPUEs for the Bay of Biscay - OTB - cluster 1- mesh class $70-79 \mathrm{~mm}$.

\subsection{Results for GNS}

As for OTB, the same process was applied to GNS data. Its leads to the identification of 3 candidate vessel clusters (Table 6).

\begin{tabular}{|c|c|c|c|c|c|c|c|c|c|c|c|}
\hline \multicolumn{3}{|c|}{ Cluster } & \multicolumn{4}{c|}{ Vessel length $(\mathrm{m})$} & \multicolumn{4}{c|}{ Gauge (grt) } & \multicolumn{3}{c|}{ Engine power main (kw) } \\
\hline Code & Number & Min & Mean & Max & Min & Mean & Max & Min & Mean & Max \\
\hline 1 & 136 & 4.2 & 7.7 & 9.7 & 0.6 & 4.0 & 39 & 4 & 62 & 110 \\
\hline 2 & 137 & 8.2 & 10.8 & 14.8 & 2 & 11.8 & 30.2 & 70 & 147 & 331 \\
\hline 3 & 37 & 12.0 & 19.2 & 30.3 & 12 & 105.4 & 195 & 152 & 321 & 558 \\
\hline Total & 310 & & & & & & & & \\
\hline
\end{tabular}

Table 6. Values of technical characteristics per cluster.

For each cluster, evolutions in monthly and annual landing averages are shown in Figure 9. According to Figure 9 and Appendix G, all mandatory criteria are fulfilled for clusters 1 and 2. Cluster 3 is excluded at this stage since it displays an inadequate length of the time series in the Bay of Biscay. 


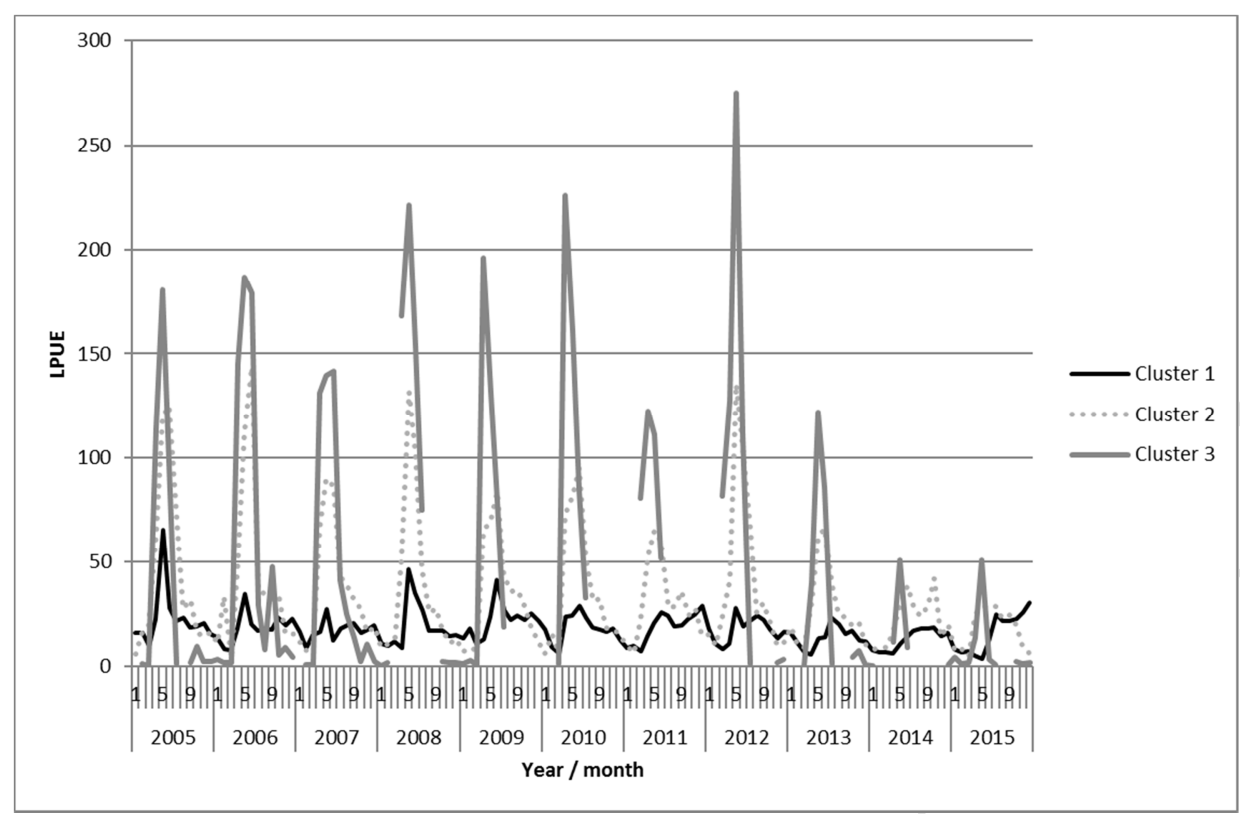

Figure 9. Average LPUEs per cluster for Surmullet in the Bay of Biscay.

Table 7 summarizes the results following the application of optional conditions on the data series.

\begin{tabular}{|l|l|c|c|c|}
\hline \multicolumn{2}{|c|}{ Multi-criteria selection method } & \multicolumn{2}{c|}{ Gear: GNS } \\
\hline \multirow{2}{*}{ Level of obligation } & Vessel typology (technical characteristics) & Cluster 1 & Cluster 2 & \multirow{2}{*}{ Cluster 3} \\
\hline \multirow{2}{*}{ Optional } & $\begin{array}{l}\text { Stable seasonal signal (both in amplitude and periodicity) } \\
\text { during the series }\end{array}$ & $1 / 3$ & $2 / 3$ & \multirow{2}{*}{ Excluded } \\
\cline { 2 - 4 } & Activity present in N and S of the Bay of Biscay & $2 / 3$ & $3 / 3$ \\
\cline { 2 - 4 } & Moderate seasonal variability & $3 / 3$ & $2 / 3$ & $7 / 9$ \\
\hline \multicolumn{1}{|c|}{ Notation } & $6 / 9$ & 2 & 1 \\
\hline
\end{tabular}

Table 7. Classification of clusters for GNS.

Although the results are tight, this point system enables cluster 2 to be proposed for GNS. Appendix $\mathrm{H}$ shows the monthly evolution of the LPUEs for each gear mesh class used for cluster $2-$ GNS. We focused on the most commonly used gear mesh classes $(50-59 \mathrm{~mm}, 60-69 \mathrm{~mm}$ and higher than 90 $\mathrm{mm}$ ) to refine the characteristics of the reference fleet. All of them are relevant for GNS according to several criteria: sufficient level of LPUE, presence over a long period, representativeness of the cluster, many uses and limited confidence interval. The relevant period was defined according to the average LPUEs per month over the series 2005 to 2015 for each class: quarters 2 and 3 for 50 - 59 $\mathrm{mm}$ gear mesh, quarter 2 for the two others (Figure 10 to Figure 12). 


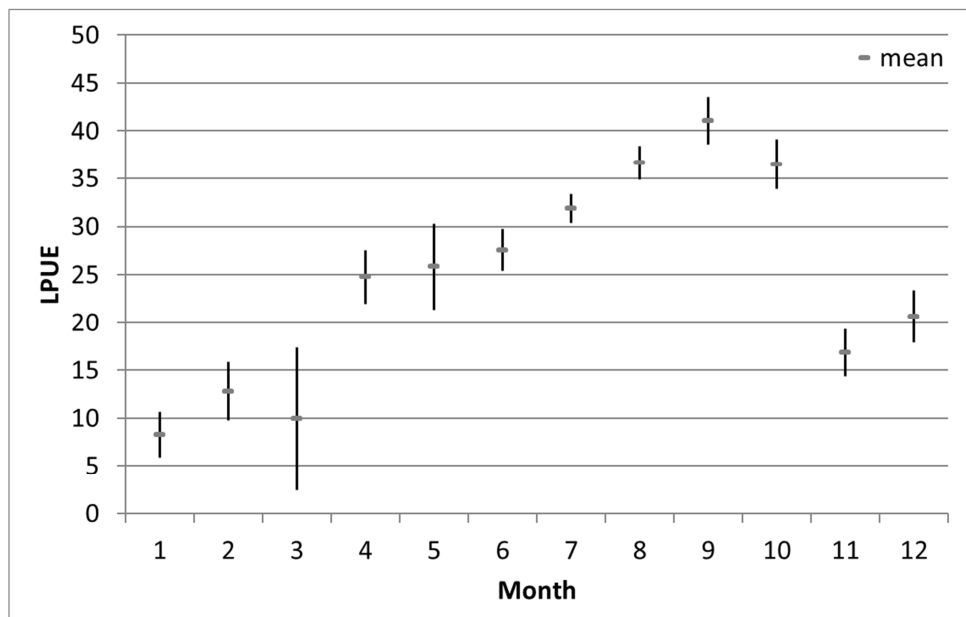

Figure 10. Average LPUEs per month over the series 2005 to 2015 for cluster 2 - GNS - 50 - 59 mm.

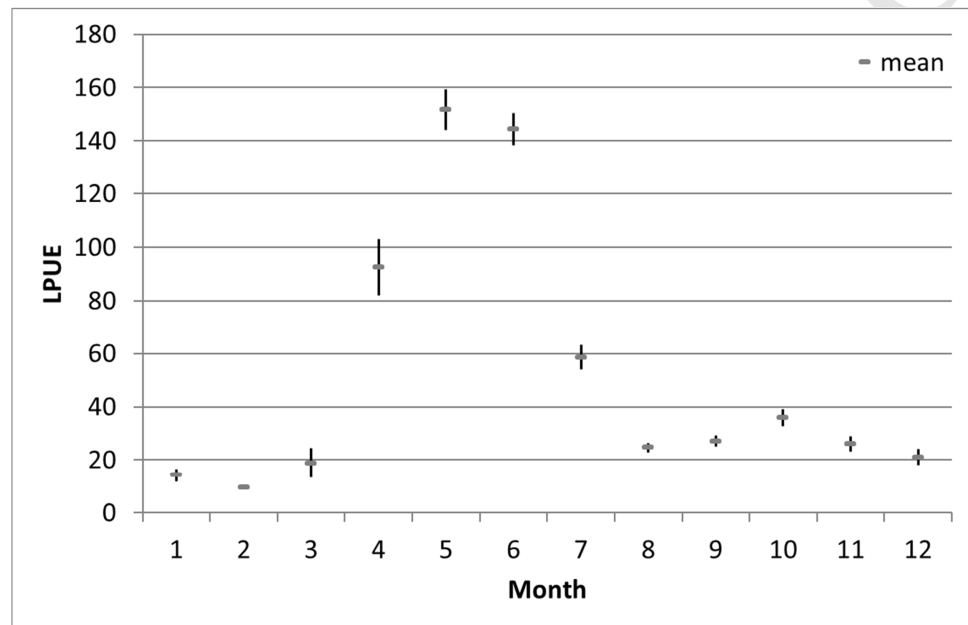

Figure 11. Average LPUEs per month over the series 2005 to 2015 for cluster 2 - GNS - 60 - $69 \mathrm{~mm}$.

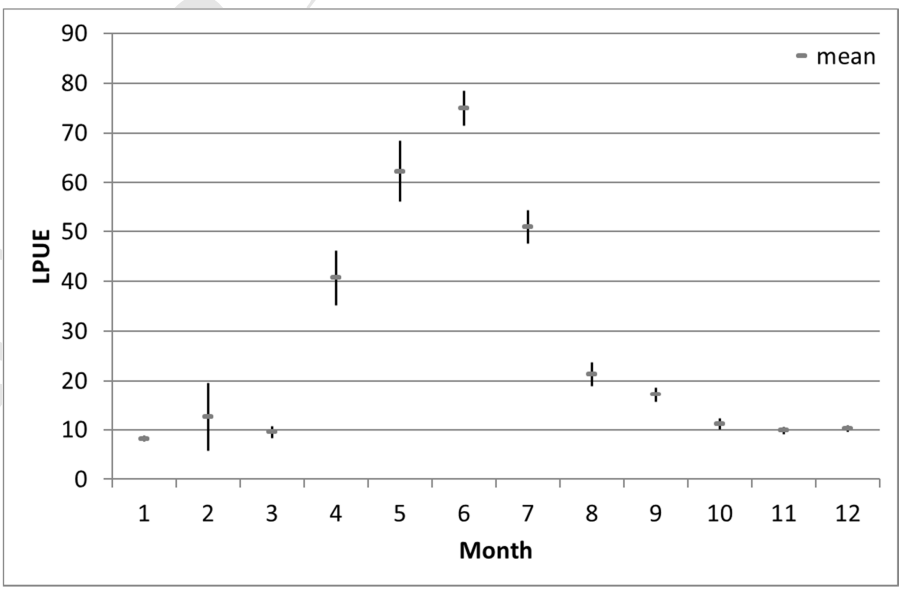

Figure 12. Average LPUEs per month over the series 2005 to 2015 for cluster 2 - GNS - greater than $90 \mathrm{~mm}$. 
For each of these combinations mesh / quarter of cluster 2 - GNS, the evolution of their use over time and of their LPUEs for the entire Bay of Biscay is considered (Figure 13 to Figure 16). Gear meshes $50-59 \mathrm{~mm}$ and $60-69 \mathrm{~mm}$ have their use levels that decrease significantly for the second quarter. For the gear mesh $60-69 \mathrm{~mm}$, this decrease is in conjunction with a significant decrease of the LPUEs over the period. For the other couples of gear mesh classes / quarter, the numbers of uses and the LPUEs seem to decrease but it is not significant.

407
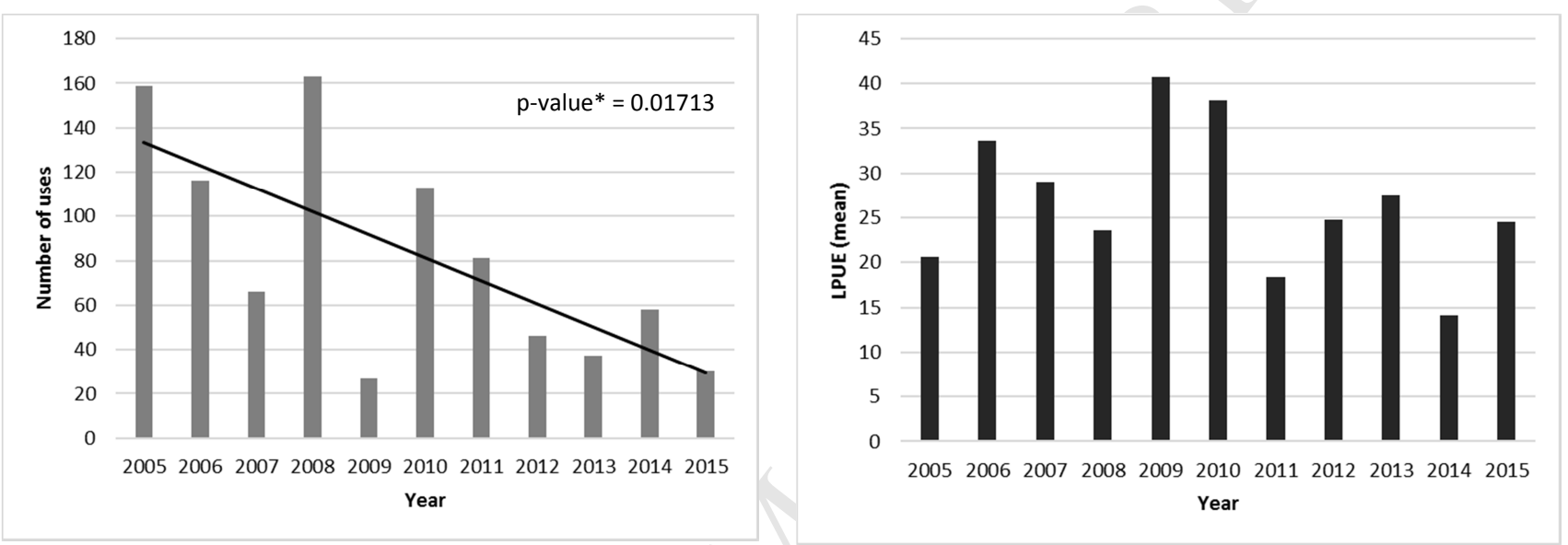

Figure 13. Number of uses and levels of associated mean LPUEs for the Bay of Biscay - 2nd quarter -
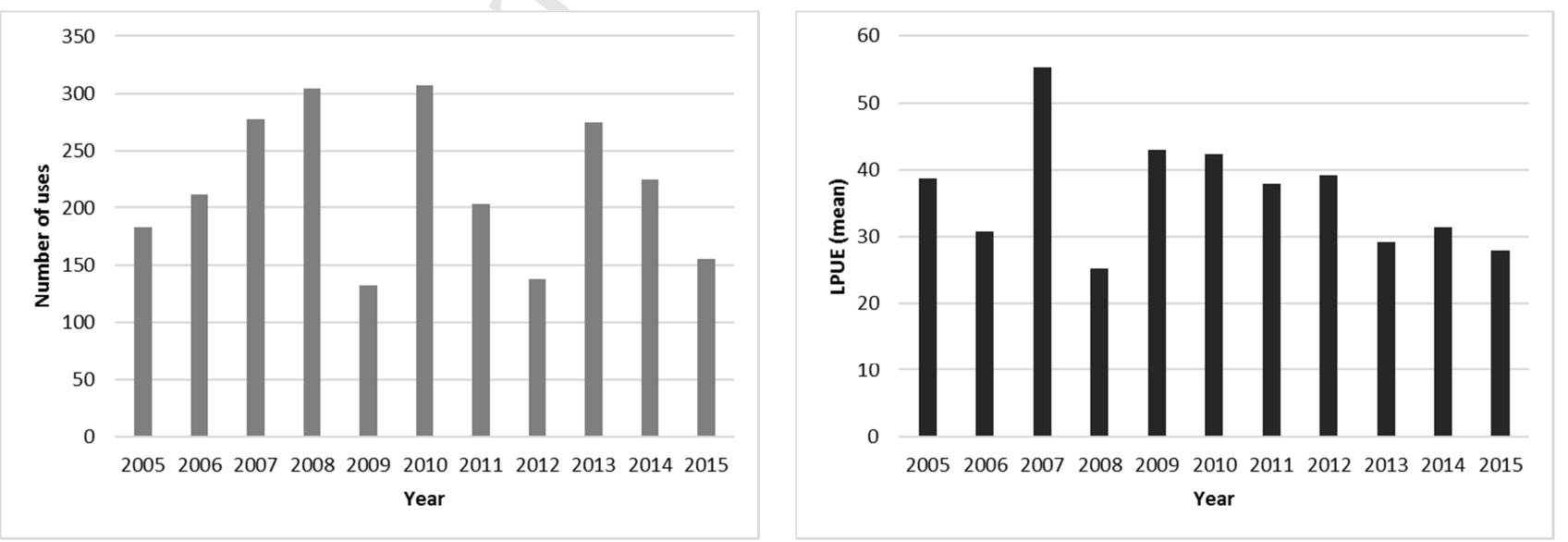

Figure 14. Number of uses and levels of associated mean LPUEs for the Bay of Biscay - 3rd quarter - 

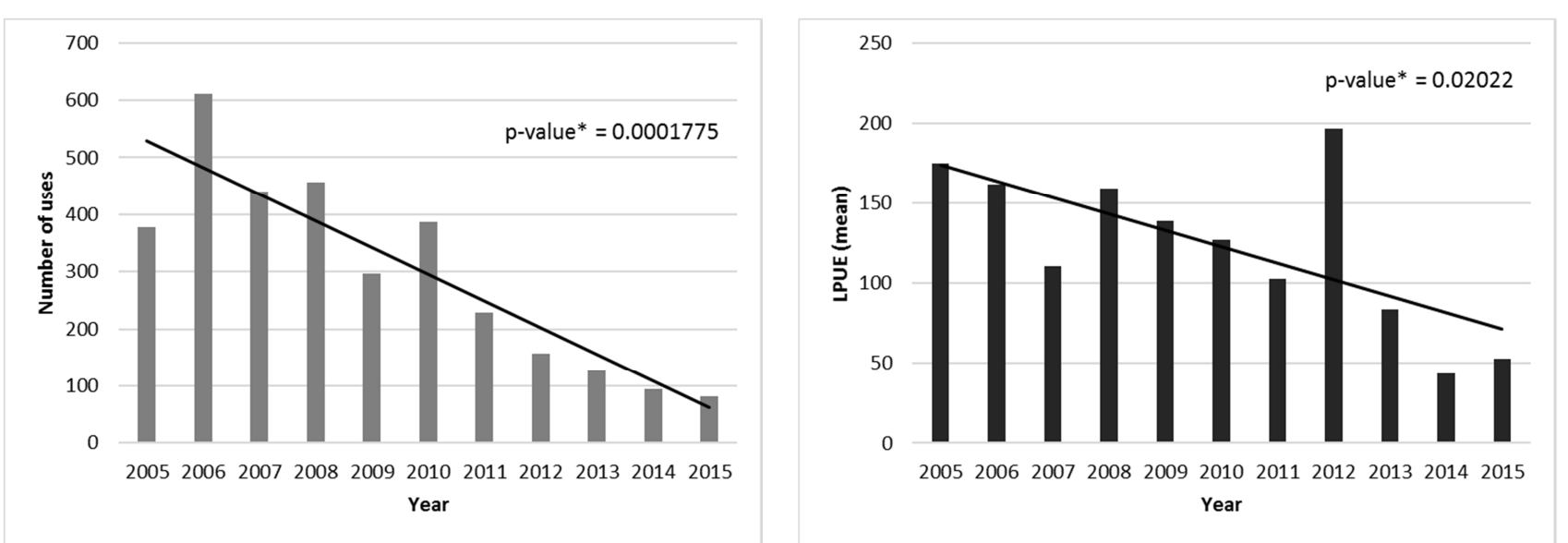

414

415

416

417

Figure 15. Number of uses and levels of associated mean LPUEs for the Bay of Biscay - 2nd quarter GNS - cluster 2 - gear mesh class 60 - $69 \mathrm{~mm}$.
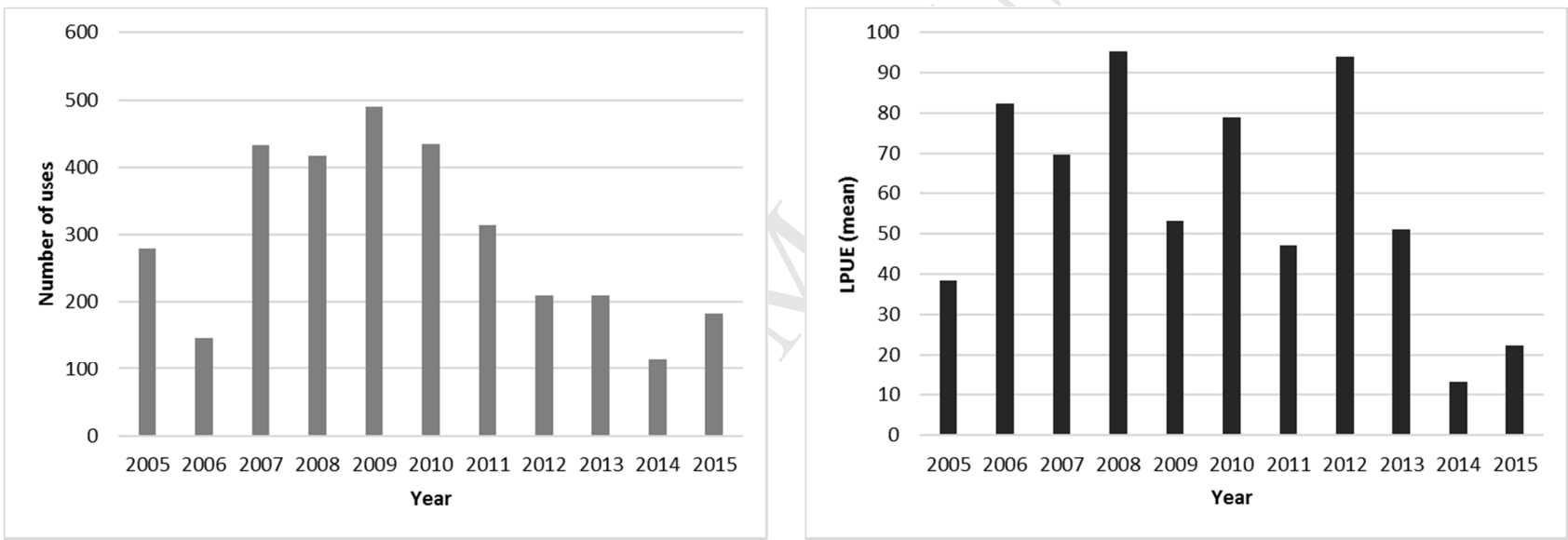

Figure 16. Number of uses and levels of associated mean LPUEs for the Bay of Biscay - 2nd quarter GNS - cluster 2 - gear mesh class higher than $90 \mathrm{~mm}$.

Starting with 5 potential fleets of interest (OTB, OTT, GNS, GTR, SDN), the analyses of the discards and the analytical process of the landing data lead us to propose two reference fleets: OTB and GNS defined by technical characteristics of the vessels, mesh class and, in the case of GNS, with temporal selection. 


\subsection{Various origins of bias identified and choices to overcome them}

One of the first sources of difficulties experienced when working on commercial fisheries data is linked to the nature of the available data. Most of the time, only landing data are available. That necessitates being well versed in the conditions under which the catches are made and, in particular, the possible effects of discards when landing based abundance indices are considered. For some species, discards can be assumed to be virtually absent (Guijarro et al., 2009; Sbrana et al., 2006). For others it is not the case (Lorance and Dupouy, 2001); discarding of marketable fish may bias CPUE (Quirijns et al., 2008). These two variables are often assimilated (García-Rodríguez et al., 2006; Quirijns et al., 2008) for small scales fisheries (e.g. Surmullet, octopus) and yet, this simplification may result in additional uncertainty. That is why we undertook a preliminary study of the discards using OBSMER data. This information, based on sampling of fishing trips, displays very low and stable percentages of discards with restricted confidence intervals for trawlers. For netters, only gillnetters presented satisfactory results (low and stable releases except in January and November). Trammel netters and Danish seiners were eliminated at this point. For the former, percentages of discards were not only high in certain months but also presented an important range of confidence intervals throughout the year. They are far from negligible and induce too high a level of uncertainty in any relative index of abundance from landings. For the latter, its exclusion comes from a lack of observed quantified data while important discards have been noted, notably on small individuals at the beginning of the implementation of the technique (Léauté et al., 2018).

Another source of known bias is related to catchability modifications (Laurec and Le Guen, 1981). Fish stock or fleet dynamics contribute in how catchability changes over time and various studies have already focused on these aspects (Kendrick et Bentley, 2010; Maunder et al., 2006; Paloheimo and Dickie, 1964; Rose and Kulka, 1999). This simple basic relationship between catchability and abundance is particularly affected when fishes aggregate (Maunder et al., 2006). No such behaviour 
449

450

451

452

453

454

455

456

457

458

459

460

461

462

463

464

465

466

467

468

469

470

471

472

473

is described for Surmullet (Caill-Milly et al., 2017). This does not preclude taking into account the ecology of the species when the spatial extent of the study area was fixed. Only the statistical ICES rectangles consistent with the bathymetric distribution of Striped red mullet that is less than or equal to 300 m (Mahé et al., 2005, Suquet and Person-Le Ruyet, 2001) were selected. Another aspect is that catchability of a species can be greatly affected when a fleet changes its targeting practice from one species to another. It also often increases over time as the efficiency of the fleet increases (Maunder et al., 2006). Due to strategies, Bourdaud et al. (2017) suggest that fishermen target rather than sample fish densities. Lorance and Dupouy (2001) highlighted a possible effect of the fishing strategy on the amount of effort expended on species due to the accuracy of the catch and effort data available (statistical rectangles versus trawl hauls). Cooperation between vessels targeting the same species can increase their ability to locate areas of high abundance and thereby increase the CPUEs of each vessel (Hilborn and Walters, 1992). We consider this is not the case for the retained gears. Surmullet is part of a set of sought-after demersal species (but not specifically targeted) both for trawlers and for netters, mainly for its high commercial value. It would certainly have been different if Danish seiner had been selected because the implementation of this type of seine appeared in the late 2000s (Léauté et al., 2018).

Distinguishing between causes related to fleet dynamics and management measures is not always obvious. However, in some cases, the relationship is highlighted and management measures can clearly interfere with the studied indices (Maunder et al., 2006). We detected clear changes in the trend of landings per fishing trip in 2005 for trawlers and netters. Discussions with professional fishermen and their representatives associated with this work enabled these observations to be linked to the implementation of a selectivity device confirmed later by the Council Regulation (EC) (No 1288/2009). To overcome this regulatory bias, we focused the analysis on the 2005-2015 period. For many fisheries, a quota consumption effect is also described (Maunder et al., 2006; Quirijns et al., 2008). This is not the case here seeing as Striped red mullet is not a quota species at this stage. 


\subsection{Main factors influencing LPUEs}

475

476

477

478

479

480

481

482

483

484

485

486

487

488

489

490

491

492

493

494

495

496

497

498

We chose to undertake a data filtering approach and not a classic statistical analysis on all of the data. While GLMs have been used since the 1980 's, they exhibit limitations in the relationship between the CPUE and the explanatory variables as they are relative to linear relationships. In a generally nonlinear world, analyses should account for relationships that are more complicated. General additive models, neural networks and regression trees are for example more general in their functional forms than GLMs (Hinton and Maunder, 2003). Habitat based models use in addition analytical reasoning to define this functional form of the relationship between CPUE and the explanatory variables (Hinton and Nakano, 1996 in Hinton and Maunder, 2003).

Both NPCA and regression trees highlighted the strong concomitance between spatiotemporal variables and LPUEs (level, variability). Such results were expected and are widely recognised in the literature (Denis et al., 2002; Gladston et al., 2018; Goodyear, 2003; Zhang et al., 2015). For OTB, it is more pronounced regarding spatial considerations, the south being characterized by higher LPUEs. However when clusters are considered, the differences are less obvious. Caill-Milly et al. (2017) described a level of landing per statistical rectangle strong enough along the whole coast (especially corresponding to depths of less than $100 \mathrm{~m}$ ) which would indicate that it makes sense to keep information from the Bay of Biscay and not to make any spatial restrictions when selecting the fleets. For GNS, important differences are detected regarding spatial considerations but they concern three statistical rectangles. They were too sparse to lead to spatial selection. In contrast, monthly differences appear important and are indeed confirmed at the cluster level. This instigated the application of a time filter for this gear. Such selection is applied for gill nets catches in lakes (Lauridsen et al., 2008); it seems less common for trawlers.

Once those spatiotemporal variables had been removed, non-linear links between LPUEs and characteristics of the vessels and of the gears appeared. For OTB, it concerns gear mesh size and engine power. Such a result is concordant with what Rijnsdorp et al. (2000) already demonstrated, in 
that CPUE of beam trawlers is strongly affected by the engine power of the vessel. For GNS, it concerns gear mesh, length and tonnage of the vessel. Again, these results are consistent with work done by Kalaycı and Yeşilçiçek (2014) and Marchal et al. (2006).

502

503

Abundance series in general showed high variability. Some aspects can be attributed to the use of various gear meshes and that is why optional criteria were applied to limit the variability in the LPUE data (for both otter trawlers and set gillnetters). For set gillnetters, the activity is seasonal. Fishermen tend to target other species the rest of the year; in fact they use nets that are not suitable for catching Striped red mullet.

\subsection{An original approach in line with ICES expectations regarding DLS}

The approach we implemented is different from most work on CPUE (or LPUE) in that it relies on a collaborative approach that associated scientists and fishermen to better identify the sources of variability of the studied variables and define the thresholds applied. This association contributes to maximising usefulness of the available data for this stock. This was the case in particular for the validation of the minimum level of LPUE, the coherent grouping of the gear meshes regarding management measures, the validation of seasonal selections, but also professional practices, the identification of regulations concomitant to trend changes in the dataset or the removal of some gears from the analysis. Such beneficial relationships between scientists and fishermen were described by Wilson (1999). They also contribute to a common ground in the course of discussions between fishermen, fisheries managers and scientists on the state of the stock (Quirijns et al., 2008). It is also innovative because it proposes prior consideration of the impact of discards on landings, which are in most cases the only real data available to study catches. However, discarding practices on which information is often limited can be of concern when using CPUE or LPUE as proxy of abundance (Rijnsdorp et al., 2007). The original aspect of the approach is also based on ecology or life-history considerations which can potentially have an important impact on the studied variables (Figueiredo et al., 2013; Laurec and Le Gall, 1975). All these data were used in a complementary way. 
It is a possible response to what is expected from ICES for DLS, which is, valuing all the available data to improve knowledge on the stock status (Le Quesne et al., 2013). We make use of the wealth of various information available (e.g. biology, population dynamics, and total catches) as recommended by Maunder et al. (2006). Decisions on how to improve management of data-deficient stocks need to be balanced with practical considerations (ICES, 2012). Indeed, particularly for DLS, it requires a continuous balance between improving data collection and reporting, refining assessment methods adapted to limited data, and developing robust management control rules (ICES, 2012).

Other approaches have been developed recently to overcome the aforementioned issues. It is particularly the case of the simultaneous implementation of commercial fishing data (CPUE) and PRCF (partial rate correlation function) to see contributions of endogenous and exogenous factors (Vazquez-Prada, 2014). Bourdaud et al. (2017) and Kristensen et al. (2014) also proposed combined valorisations of commercial fisheries data and scientific surveys data. This work contributes at its respective level to one of the objectives of ICES that is increasing the number of DLS European Atlantic waters with quantitative catch advice (Le Quesne et al., 2013). For Surmullet, they reduce somewhat the gap regarding knowledge between this studied stock and the one found in Subarea 4 (North Sea), Divisions 7.d (Eastern English Channel) and 3.a (Skagerrak, Kattegat). A considerable research effort has been conducted for almost fifteen years on these particular divisions (Mahé et al., 2005; Mahé et al., 2013).

For the Striped red mullet in Subareas and Divisions 6, 7a-c, e-k, 8, and 9a, the target category is category 4 (ICES, 2013). The two selected fleets can provide a solution to emerge from the current situation (applying the precautionary buffer) and use catch information to evaluate whether the stock is fished sustainably or whether a reduction in catches or landings is required to achieve sustainability. In this case, the landing reduction recommended by ICES in 2017 was adapted to the situation, as the retained abundance indicators appear to decrease significantly in two out of four 
cases over the period. Nevertheless, in the absence of any existing measures to limit catches, this recommendation may not be followed in reality.

\section{Conclusions}

This study considered the factors affecting landing rates (LPUE) of M. Surmuletus Bay of Biscay French fisheries over an eleven-year period and enabled us to determine the relative contribution of fleet technical characteristics (vessels and gears) and intra- and inter-annual variation. It led to the identification of two reference fleets. Firstly the trawlers composed by small vessels $(7.9-15.8 \mathrm{~m})$ with a gauge of 2 to $43.9 \mathrm{grt}$, an engine power between 44 and $256 \mathrm{~kW}$ and a gear mesh of $70-79$ $\mathrm{mm}$; secondly the gillnetters, which are defined by medium-sized vessels $(8.2-14.8 \mathrm{~m}, 2-30.2 \mathrm{grt}$, $70-331 \mathrm{~kW}$ ) whose gear mesh is either $50-59 \mathrm{~mm}$ (2nd and 3rd quarters), $60-69 \mathrm{~mm}$ (2nd quarter) or greater than $90 \mathrm{~mm}$ (2nd quarter). LPUE of these fleets show a downward trend, significant in two out of four cases that may reflect deterioration in the status of the Striped red mullet stock.

The complementary use of various sources of data (fisheries data, ecological considerations, professional knowledge) is a solution for selecting reference fleet. A filtering approach could be implemented on other DLS-whiting and pollack for instance. We can state that this study approach is both innovative and can be applied more generally.

Since it is considered that the retained LPUEs are proxy of abundance, they can also be used to detect spatiotemporal variability of abundance in relation to environmental forcing, especially those that can be linked to climate change. For such a purpose, the use of GLM or other statistical models (taking into account their predictive power) will be very useful and are currently being tested using the knowledge ascertained in this paper. 


\section{Acknowledgments}

573 This work was supported by France Filière Pêche on the thematic focus - acquisition of knowledge on

574 the fishery resources [convention number $\mathrm{PH} / 2014 / 16$ ].

575 We thank all the people involved in the collection of fishery statistics. Like other papers using this

576 data, this work could not have been done without this time-consuming work and their commitment.

577 The authors wish to thank Lorna Miskelly for English editing and Florence Sanchez for all her advice

578 on the manuscript.

579 The manuscript was greatly improved by comments from two anonymous reviewers.

580

581 No conflicts of interests

582 We declare that we have no conflict of interest. 
584

585

586

587

588

589

590

591

592

593

594

595

596

597

598

599

600

601

602

603

604

605

\section{References}

Benzinou, A., Carbini, S., Nasreddine, K., Elleboode, R., and Mahé, K., 2013. Discriminating stocks of Striped red mullet (Mullus surmuletus) in the Northwest European seas using three automatic shape classification methods. Fish. Res. 143, 153-160.

Bourdaud, P., Travers-Trolet, M., Vermard, Y., Cormon, X., and Marchal, P., 2017. Inferring the annual, seasonal, and spatial distributions of marine species from complementary research and commercial vessels' catch rates. ICES J. Mar. Sc. 74(9), 2415-2426. Publisher's official version: http://doi.org/10.1093/icesjms/fsx092

Caill-Milly, N., Lissardy, and M. Léauté, J.-P., 2017. Improvement of the fishery knowledge of Striped red mullet of the Bay of Biscay. Working Document for the Working Group on Widely Distributed Stocks (WGWIDE), 30 August - 5 September 2017, Copenhagen (Denmark), 30 p.

Cornou, A.-S., Quinio-Scavinner, M., Delaunay, D., Dimeet, J., Goascoz, N., Dube, B., Fauconnet, L., and Rochet, M.-J. 2015. Observations à bord des navires de pêche professionnelle. Bilan de l'échantillonnage 2014. http://dx.doi.org/10.13155/39722

Davis, P.S. and Edward, A.J. 1988. New records of fishes from the northeast coast of England, with notes on the rediscovery of part of the type collection of marine fishes from the Dove Marine Laboratory, Cullercoats. Trans. Nat. Hist. Soc. Northumbria. 55, 39-46.

De'ath, G. and Fabricius K. E., 2000. Classification and Regression Trees: a powerful yet simple technique for ecological data analysis. Ecology, 81(11), 2000, 3178-3192.

Demanèche, S., Bégot, E., Gouëllo, A., Campéas, A., Habasque, J., Merrien, C., Leblond, E., Berthou, P., Harscoat, V., Fritsch, M., Leneveu, C., and Laurans, M., 2013. PROJET SACROIS « IFREMER / DPMA » V 3.2.5 - 11/2013. 43 p. 
Denis, V., Lejeune, J., and Robin, J. P., 2002. Spatio-temporal analysis of commercial trawler data using General Additive models: patterns of Loliginid squid abundance in the north-east Atlantic. ICES J. Mar. Sc. 59, 633-648. doi:10.1006/jmsc.2001.1178

Figueiredo, I., Natário, I., Moura, T., and Carvalho, M. L., 2013. Modelling the dynamics of the deepwater shark Centroscymnus coelolepis off mainland Portugal. Aquat. Living Resour. 26, 355-364.

Gibson, R.N. and Robb, L. 1997. Occurrence of juvenile red mullet (Mullus surmuletus) on the west coast of Scotland. J. Mar. Biol. Assoc UK. 77(3): 911-912.

Girard, M., Lorance, P., and Biseau, A., 2000. Catch Per Unit Effort of deep-sea species off the continental slope to the west of British Isles. Cybium 24(3), 97-104.

García-Rodríguez, M., Fernández A.M., and Esteban, A., 2006. Characterisation, analysis and catch rates of the small-scale fisheries of the Alicante Gulf (SE Spain) over a 10 years time series. Fish. Res. 77(2), 226-238. doi: 10.1016/j.fishres.2005.09.002

Gladston, Y., Martin Xavier, K. A., Ajina, S. M., Om Pravesh Kumar Ravi, Manoharmayum Shaya Devi, Thakurdas, Chakraborty, S. K., and Latha Shenoy, 2018. Operational performance and catch composition of pomfret gillnets of Maharashtra, India. Reg. Stud. Mar. Sc. 22, 31-37.

Goodyear, C. P., 2003. Spatio-temporal distribution of longline catch per unit effort, sea surface temperature and Atlantic marlin. Mar. Freshwater Res. 54(4), 409-417.

Guijarro, B., Massutí, E., Moranta, J. E., and Cartes, J., 2009. Short spatio-temporal variations in the population dynamics and biology of the deep-water rose shrimp Parapenaeus longirostris (Decapoda: Crustacea) in the western Mediterranean. Sci. Mar. 73(1), 183-197, doi: 10.3989/scimar.2009.73n1183 
Hilborn, R. and Walters, C. J., 1992. Quantitative Fisheries Stock Assessment: Choice, Dynamics \& Uncertainty. Chapman and Hall, London. 570 pp.

Hinton, R. and Maunder, M. N.,2003. Methods for standardizing cpue and how to select among them. SCTB16 Working Paper MWG-7, 13 pp.

ICES, 2012. Report of the Working Group on the Assessment of Demersal Stocks in the North Sea and Skagerrak (WGNSSK), 27 April - 03 May 2012, ICES Headquarters, Copenhagen. ICES CM 2012/ACON:13. 1346 p.

ICES, 2013. Report of the Workshop on the Development of Quantitative Assessment Methodologies based on LIFE-history traits, exploitation characteristics, and other key parameters for Datalimited Stocks (WKLIFE III), 28 October-1 November 2013, Copenhagen, Denmark. ICES CM 2013/ACOM:35, 98 pp.

ICES. 2016. Advice basis. In Report of the ICES Advisory Committee, 2016. ICES Advice 2016, Book 1, section 1.2.

http://www.ices.dk/sites/pub/Publication\%20Reports/Advice/2016/2016/Introduction_to_a dvice_2016.pdf

ICES, 2017. Advice on fishing opportunities, catch, and effort Bay of Biscay and the Iberian Coast, Celtic Seas. Greater North Sea, and Oceanic Northeast Atlantic Ecoregions. DOI: 10.17895/ices.pub.3032 mur.27.67a-ce-k89a, 5 pp.

Kalaycı, F. and Yeşilçiçek, T., 2014.Effects of Depth, Season and Mesh Size on the Catch and Discard of Whiting (Merlangius merlangus euxinus) Gillnet Fishery in the Southern Black Sea, Turkey. Turk. J. Fish. Aquat. Sc. 14, 449-456.

Kendrick T. H. and Bentley N., 2010. Fishery characterisation and catch-per-unit-effort indices for trevally in TRE 7, 1989-90 to 2007-08. New Zeal. Fish. Rep. 41, 58 pp. 
Kristensen, K., Thygesen, U.H., Andersen, K.H., and Beyer, J.E., 2014. Estimating spatio-temporal dynamics of size-structured populations. Can. J. Fish. Aquat. Sci. 71: 326-336.

Laurec, A. and Le Gall, J.-Y., 1975. De-seasonalizing of the abundance index of species. Application to the albacore (Thunnus alalunga) monthly catch per unit of effort (C.P.U.E.) by the Atlantic Japanese longline fishery. Bull. Far. Seas Fish. Res. 12, 145-169.

Laurec, A. and Le Guen, J.-C., 1981. Dynamique des populations marines exploitées. Tome 1. Concepts et modèles. Publications du C.N.E.X.O. Série "Rapports scientifiques et techniques", (45), 1-120. Open Access version: http://archimer.ifremer.fr/doc/00000/1126/

Lauridsen, T. L., Landkildehus, F., Jeppesen, E., Jørgensen, T. B., and Søndergaard, M., 2008. A comparison of methods for calculating Catch Per Unit Effort (CPUE) of gill net catches in lakes. Fish. Res. 93, 204-211.

Léauté, J.-P., Caill-Milly, N., Lissardy, M., Bru, N., Dutertre, M.-A., and Saguet, C., 2018. ROMELIGO. Amélioration des connaissances halieutiques du ROuget-barbet, du MErlan et du Lleu jaune du GOlfe de Gascogne. RBE/HGS/LRHLR et ODE/UL/LERAR/18-001. http://archimer.ifremer.fr/doc/00440/55126/

Le Quesne, W., Brown, M., De Oliveira, J., Casey, J., and O’Brien, C., 2013. Rapport parlement européen DATA-DEFICIENT FISHERIES IN EU WATERS - STUDY, 74 pp.

Lorance, P. and Dupouy, H., 2001. CPUE abundance indices of the main target species of the French deep-water fishery in ICES Sub-areas V-VII. Fish. Res. 51(2-3), 137-149.

Mahé, K., Destombes, A., Coppin, F., Koubbi, P., Vaz, S., Le Roy, D., and Carpentier, A., 2005. Le rouget barbet de roche Mullus surmuletus (L. 1758) en Manche orientale et mer du Nord. Rapport de Contrat IFREMER/CRPMEM Nord-Pas-de-Calais, 187p. 
Mahé, K., Coppin, F., Vaz, S., and Carpentier, A., 2013. Striped red mullet (Mullus surmuletus, Linnaeus, 1758) in the eastern English Channel and southern North Sea: growth and reproductive biology. J. Appl. Ichthyol. 29(5), 1067-1072. Publisher's official version: http://doi.org/10.1111/jai.12266

Marchal, P., Andersen, B., Caillart, B., Eigaard, Guyader, O., Hovgaard, H., Iriondo, A., Le Fur, F., Sacchi, J., and Santurtun, M. 2007. Impact of technological creep on fishing effort and fishing mortality, for a selection of European fleets. ICES J. Mar. Sci. 64, 192-209.

Maunder, M. N., Sibert, J. R., Fonteneau, A., Hampton, J., Kleiber, P., and Harley, S. J., 2006. Interpreting catch per unit effort data to assess the status of individual stocks and communities. ICES J. Mar. Sci. 63, 1373-1385. doi:10.1016/j.icesjms.2006.05.008

Maynou, F., Demestre, M. and Sánchez, P., 2003. Analysis of catch per unit effort by multivariate analysis and generalised linear models for deep-water crustacean fisheries off Barcelona (NW Mediterranean). Fish. Res. 65(1-3), 257-269.

O'Brien, C., 2013. Review of latest ICES' advice: Improving stocks/declining stocks/implications - and overview of global stock status. Seafish Common Language Group, $6^{\text {th }}$ November 2013, London, $37 \mathrm{p}$.

O'Brien, C., 2016. Management: New Approaches to Old Problems, in: Jakobsen, T., Fogarty, M. J., Megrey, B. A., Moksness, E., 2016. Fish Reproductive Biology: Implications for Assessment and Management - Print version: Fish reproductive biology Second edition. Chichester, West Sussex, U.K.; Hoboken, NJ: Wiley-Blackwell, 9781118752746.

Paloheimo, J.E. and Dickie, L.M., 1964. Abundance and fishing success. Rapp. P.-V. Reun. Cons. Int. Explor. Mer. 155: 152-163. 
Prasad, A M., Iverson, L. R., and Liaw, A., 2006. Newer Classification and Regression Tree Techniques: Bagging and Random Forests for Ecological Prediction. Ecosystems. 9 (2): 181-199.Quéro, J.C. and Vayne, J.J. 1997. Les poissons de mer des pêches françaises. Ifremer, Ed. Delachaux \& Niestlé, Lausanne - Paris.

Quirijns, F.J., Poos, J.J., and Rijnsdorp, A.D., 2008. Review, Standardizing commercial CPUE data in monitoring stock dynamics: Accounting for targeting behaviour in mixed fisheries. Fish. Res. $89,1-8$.

Rijnsdorp, A.D., Dol,W., Hooyer, M., and Pastoors, M.A., 2000. Effects of fishing power and competitive interactions among vessels on the effort allocation on the trip level of the Dutch beam trawl fleet. ICES J. Mar. Sci. 57, 927-937.

Rijnsdorp, A. D., Daan, N., Dekker, W., Poos, J. J., and Van Densen, W.L.T., 2007. Sustainable use of flatfish resources: Addressing the credibility crisis in mixed fisheries management. J. Sea Res. 57(2-3), 114-125. https://doi.org/10.1016/j.seares.2006.09.003

Rose, G.A. and Kulka, D.W. 1999. Hyperaggregation of fish and fisheries: how catch-per-unit-effort increased as the northern cod (Gadus morhua) declined. Can. J. Fish. Aquat. Sci. 56(1), 118127.

Sbrana, M., C. Viva, and Belcari, P., 2006. Fishery of the deepwater rose shrimp Parapenaeus longirostris (Lucas, 1846) (Crustacea: Decapoda) in the northern Tyrrhenian Sea (western mediterranean). Hydrobiologia 557, 135-144.

Shearer, C., 2000. The CRISP-DM model: the new blueprint for data mining. J. Data Warehousing 5 (4), 15.

Suquet, M. and Person-Le Ruyet, J., 2001. Les rougets barbets (Mullus barbatus, Mullus surmuletus). Biologie, pêche, marché et potentiel aquacole. Ifremer eds., Brest. 


\section{ACCEPTED MANUSCRIPT}

718 Vázquez-Prada, G., 2014. Analyzing fish stocks dynamics using CPUE and PRCF: a new approach for the fishery management. J. Coastal Life Med. 2(1), 1-6.

720 Wilson, D. C., 1999. Fisheries Science Collaborations: The Critical Role of the Community. Institute for Fisheries Management and Coastal Community Development, Res. Publ. 45, 24 p.

722 Zhang,H., Zhang, S. M., Cui, X. S., Yang, S. L., Hua, C. J., and Ma, H. Y., 2015. Spatio-temporal dynamics in the location of the fishing grounds and catch per unit effort (CPUE) for Chilean jack mackerel (Trachurus murphyi Nichols, 1920) from Chinese trawl fleets on the high seas of the Southeast Pacific Ocean, 2001-2010. J. Appl. Ichtyol. 31 (4), 646-656. https://doi.org/10.1111/jai.12765 


\section{8 \\ Appendix}

\section{Appendix A}

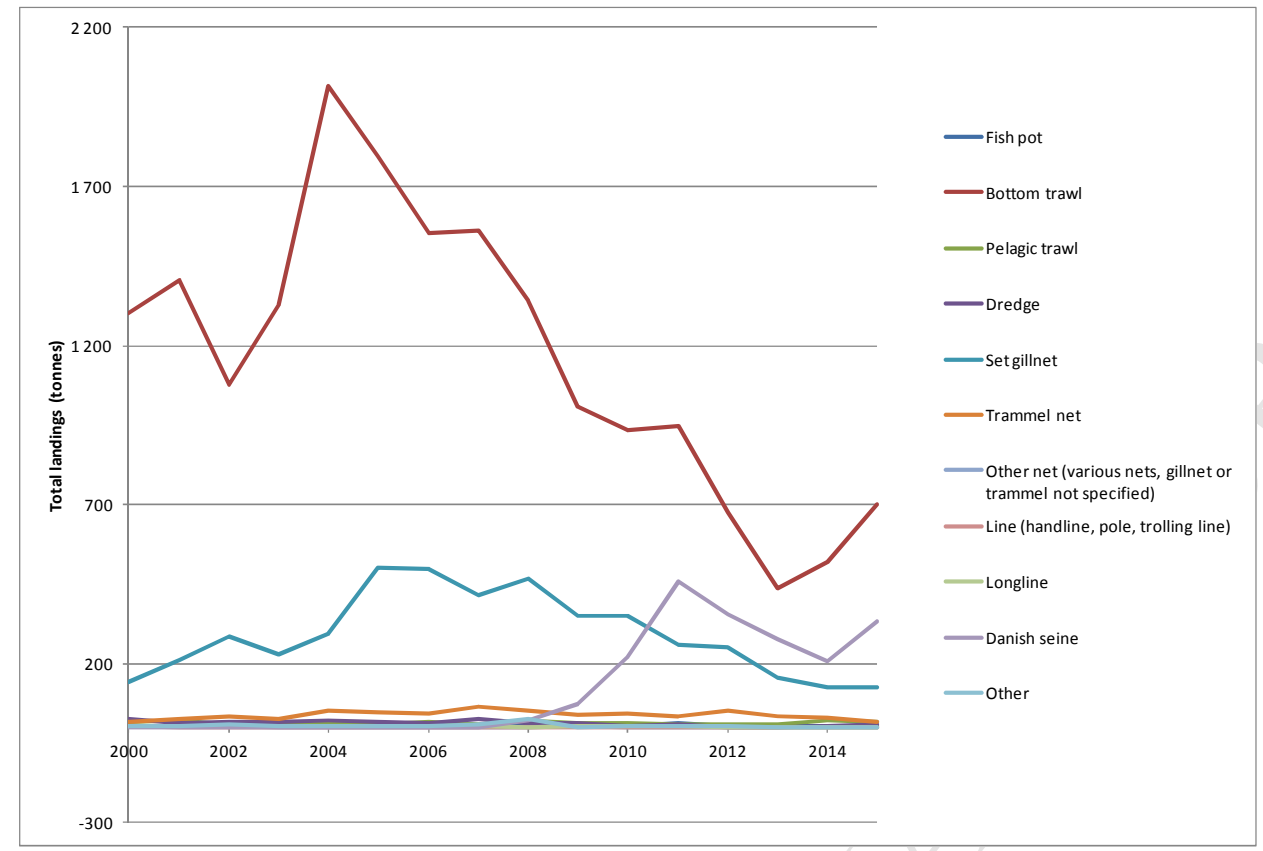

730 Figure A.1. Evolution of total landings from 2000 to 2015 by groups of gears (Sacrois data). Gear

731 representing less than 0.5 tonnes per year over the period is not specified but grouped under "other"

732 (translated from Caill-Milly et al., 2017). 
Appendix B

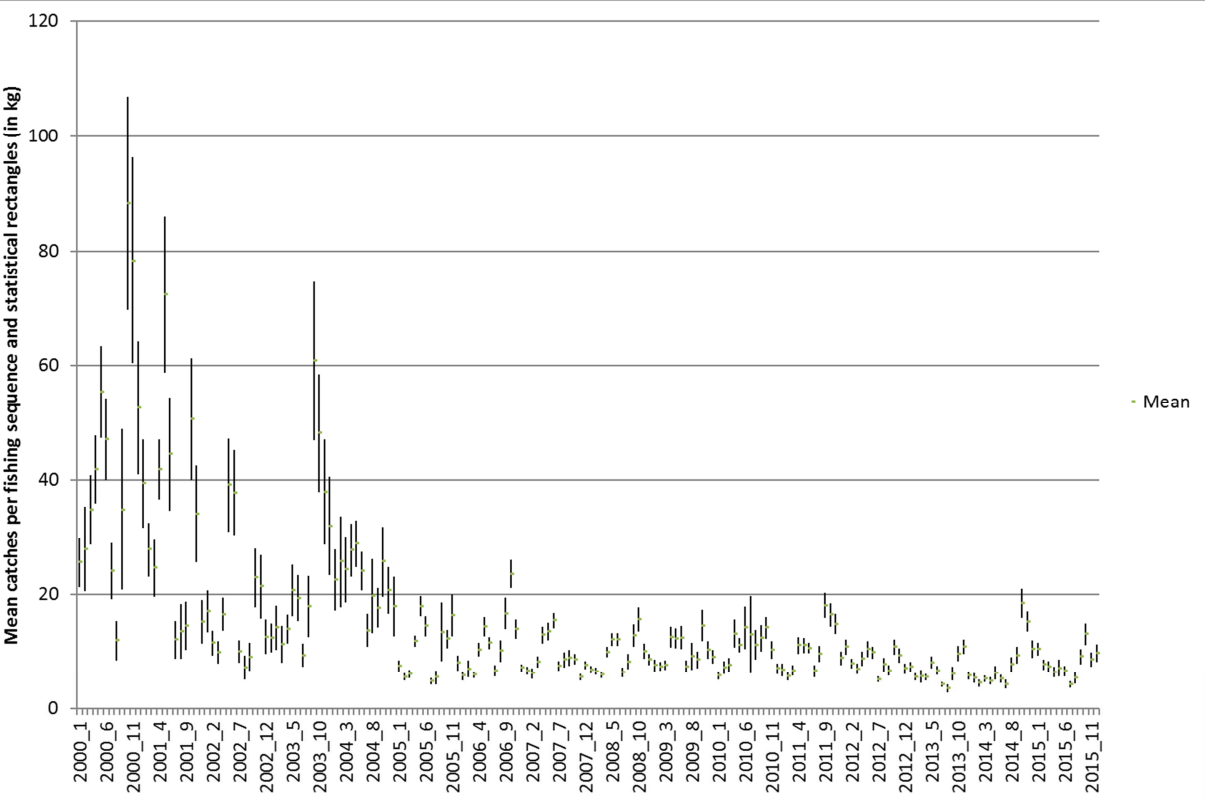

Figure B.1: Landings by fishing sequence and statistical rectangle (2000 - 2015) for Trawlers

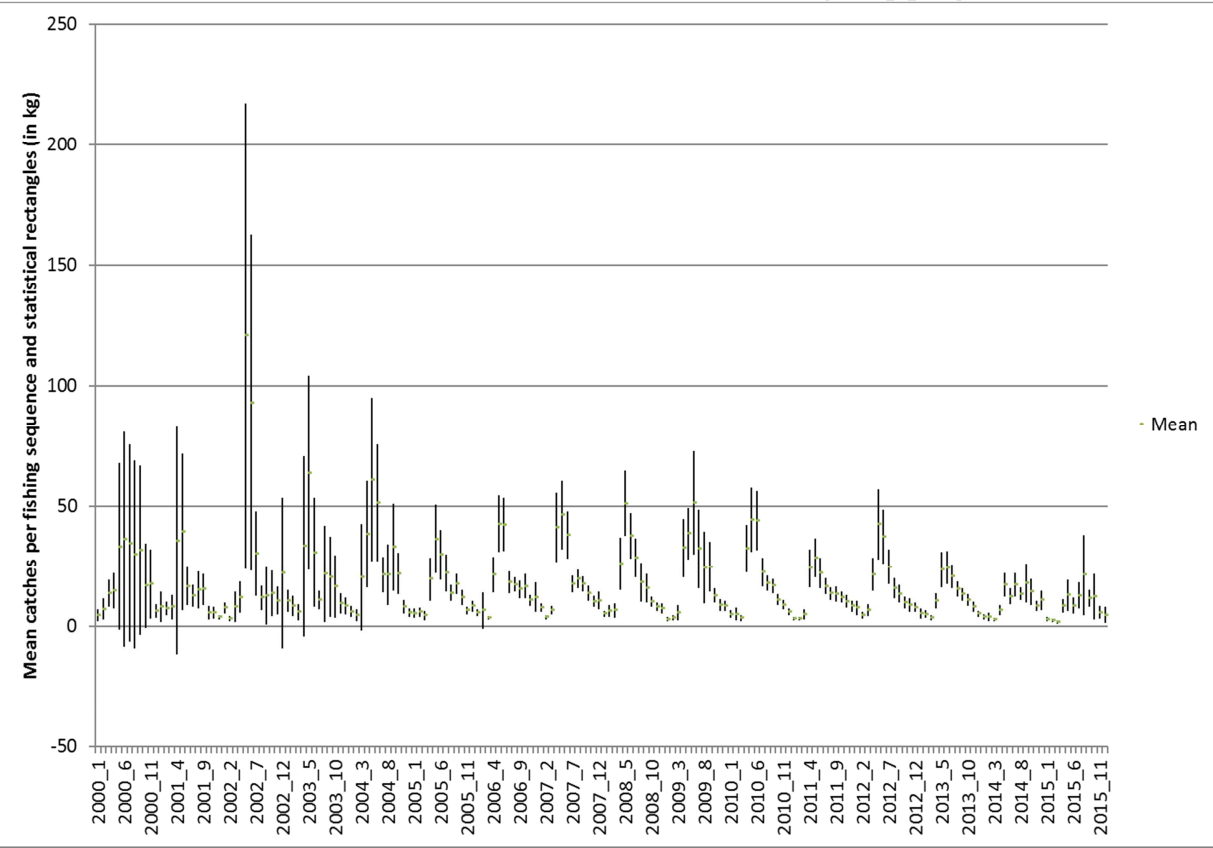




\section{Appendix C}

739 Discards data (Summary of the number of trip sequences (Obsmer) for the 4 selected gears)

\begin{tabular}{|c|c|c|c|c|c|c|c|c|c|c|c|c|c|}
\hline Years & $J A$ & $\mathrm{FE}$ & MA & $A P$ & MA & JU & JY & $\mathrm{AU}$ & SE & OC & NO & $\mathrm{DE}$ & Total \\
\hline 2004 & & & & & & & 3 & & 5 & & & & 8 \\
\hline 2005 & & & & 1 & 2 & 7 & & & & & 5 & 10 & 25 \\
\hline 2006 & & & 1 & 1 & & 1 & & & & & & 6 & 9 \\
\hline 2007 & & & & & & & & & 1 & 7 & 3 & & 11 \\
\hline 2008 & & & & & & & & & 2 & 8 & 5 & & 15 \\
\hline 2009 & & & & & 5 & 4 & 4 & 3 & 4 & 1 & & 2 & 23 \\
\hline 2010 & 2 & & 1 & 2 & 5 & 2 & 5 & 10 & 10 & 10 & 4 & 1 & 52 \\
\hline 2011 & 13 & 3 & & 2 & 9 & 7 & 7 & 9 & 11 & 12 & 3 & Y & 76 \\
\hline 2012 & 2 & 1 & & & 4 & 3 & & 6 & 13 & 4 & 4 & 3 & 40 \\
\hline 2013 & & 2 & & 1 & 6 & 6 & 3 & 7 & 6 & 1 & 3 & 2 & 37 \\
\hline 2014 & 2 & 1 & & 1 & 3 & 10 & 3 & 7 & 7 & & 5 & 5 & 44 \\
\hline 2015 & 4 & 2 & 3 & 2 & 2 & 5 & 7 & 1 & 3 & 3 & 4 & & 36 \\
\hline
\end{tabular}

741 Figure C.1. Number of trip sequences per month and year for OTB

\begin{tabular}{|l|r|r|r|r|r|r|r|r|r|r|r|r|r|r|}
\hline Years & JA & FE & MA & AP & MA & JU & JY & AU & SE & OC & NO & DE & Total \\
\hline 2004 & 1 & 2 & 1 & 2 & & & & & & & & 3 & 9 \\
\hline 2005 & 1 & 1 & & 1 & 1 & 7 & 9 & 1 & 6 & 5 & 19 & 4 & 55 \\
\hline 2006 & 1 & 1 & 3 & 2 & 3 & 12 & 3 & & 7 & 8 & 5 & & 45 \\
\hline 2007 & & 1 & 5 & & 1 & 6 & 10 & & 11 & 8 & & 13 & 55 \\
\hline 2008 & 5 & & 1 & 1 & 1 & 1 & 2 & & & 3 & & 2 & 16 \\
\hline 2009 & & & & 6 & 12 & 3 & 4 & & & 1 & 2 & 9 & 37 \\
\hline 2010 & 6 & 10 & 6 & 4 & 14 & 8 & 7 & 5 & 1 & 4 & & 6 & 71 \\
\hline 2011 & 3 & 2 & 3 & 1 & 4 & 3 & 7 & & 1 & & 3 & 3 & 30 \\
\hline 2012 & 2 & & & 3 & 2 & 7 & 7 & & & 7 & 3 & 5 & 36 \\
\hline 2013 & 11 & 2 & 6 & 1 & 6 & 18 & 7 & 2 & 1 & 4 & 3 & 6 & 67 \\
\hline 2014 & 6 & 1 & 2 & 2 & 12 & 6 & 6 & 1 & & 3 & & 4 & 43 \\
\hline 2015 & 6 & 5 & 5 & 14 & 16 & 14 & & 5 & & 1 & & 6 & 72 \\
\hline
\end{tabular}

743 Figure C.2. Number of trip sequences per month and year for OTT 


\begin{tabular}{|l|r|r|r|r|r|r|r|r|r|r|r|r|r|}
\hline Years & JA & FE & MA & AP & MA & JU & JY & AU & SE & OC & NO & DE & Total \\
\hline 2004 & & & & & & & 1 & & & 1 & 2 & & 4 \\
\hline 2005 & & & & & & 2 & & & & 1 & & \\
\hline 2007 & & & & 2 & 4 & 5 & & & 1 & & 1 & \\
\hline 2008 & & & & & 5 & 6 & & 1 & 1 & 4 & 5 & \\
\hline 2009 & & & & 3 & 7 & 7 & & 3 & & 1 & & 22 \\
\hline 2010 & 5 & 3 & 12 & 2 & 2 & 12 & 4 & & 4 & 6 & 4 & 3 & 57 \\
\hline 2011 & & 2 & & 2 & & 3 & 3 & 3 & & 2 & 4 & 3 & 22 \\
\hline 2012 & 1 & 3 & 2 & & 2 & 3 & 6 & 1 & 2 & 4 & 2 & & 26 \\
\hline 2013 & & 3 & & 1 & 4 & 3 & & 2 & 2 & 8 & 6 & 1 & 30 \\
\hline 2014 & 1 & & 3 & & & 2 & 3 & 4 & 8 & 8 & & 2 & 31 \\
\hline 2015 & 1 & & 1 & 3 & 2 & 3 & 4 & 7 & 15 & 4 & 5 & 3 & 48 \\
\hline
\end{tabular}

746 Figure C.3. Number of trip sequences per month and year for GNS

747

\begin{tabular}{|r|r|r|r|r|r|r|r|r|r|r|r|r|r|}
\hline Years & JA & FE & MA & AP & MA & JU & JY & AU & SE & OC & NO & DE & Total \\
\hline 2004 & & & & & & & 2 & & & & 4 & \\
\hline 2005 & & & & & & 1 & & & & & & & 1 \\
\hline 2006 & & & & & & & & & 1 & 1 & & & 2 \\
\hline 2007 & & & 2 & & & & & & 6 & & & & 8 \\
\hline 2008 & & 3 & 1 & 4 & 6 & & & & 3 & 6 & 5 & 5 & 33 \\
\hline 2009 & 2 & 7 & 2 & 3 & 3 & 4 & 2 & & & 2 & 2 & & 27 \\
\hline 2010 & 3 & 2 & 2 & 1 & 6 & 5 & 1 & & 12 & 15 & 2 & 2 & 51 \\
\hline 2011 & 1 & 4 & 3 & 4 & 2 & 1 & 2 & 2 & 1 & 4 & 1 & & 25 \\
\hline 2012 & 3 & & & 2 & 3 & & 1 & & 2 & 2 & 1 & 1 & 15 \\
\hline 2013 & & 10 & & & 2 & 1 & 1 & & 1 & 1 & & & 16 \\
\hline 2014 & & & & & 6 & & 5 & 6 & 6 & 8 & 14 & & 45 \\
\hline 2015 & 2 & 1 & 1 & 4 & 3 & & & 4 & 3 & 4 & 8 & 2 & 32 \\
\hline
\end{tabular}

748 Figure C.4. Number of trip sequences per month and year for GTR 
750 Appendix D

751 Discards analyses

752 ОТВ

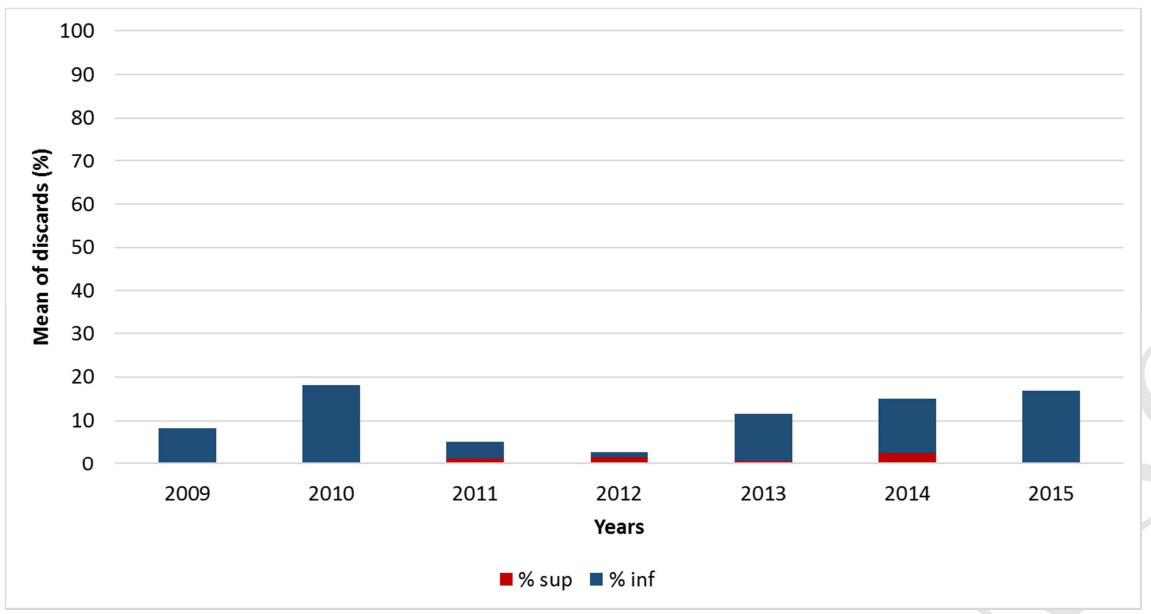

753 Figure D.1. Discard mean for all the series for OTB (2009-2015) per year in \%

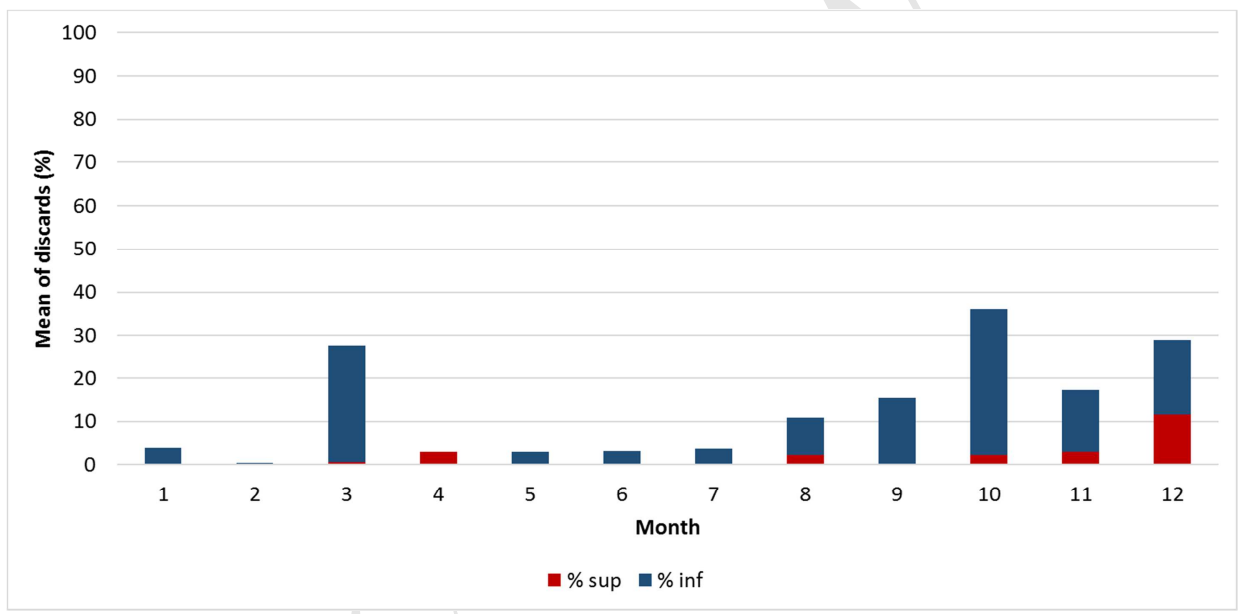

Figure D.2. Discard mean for all the series for OTB (2009-2015) per month in \% 


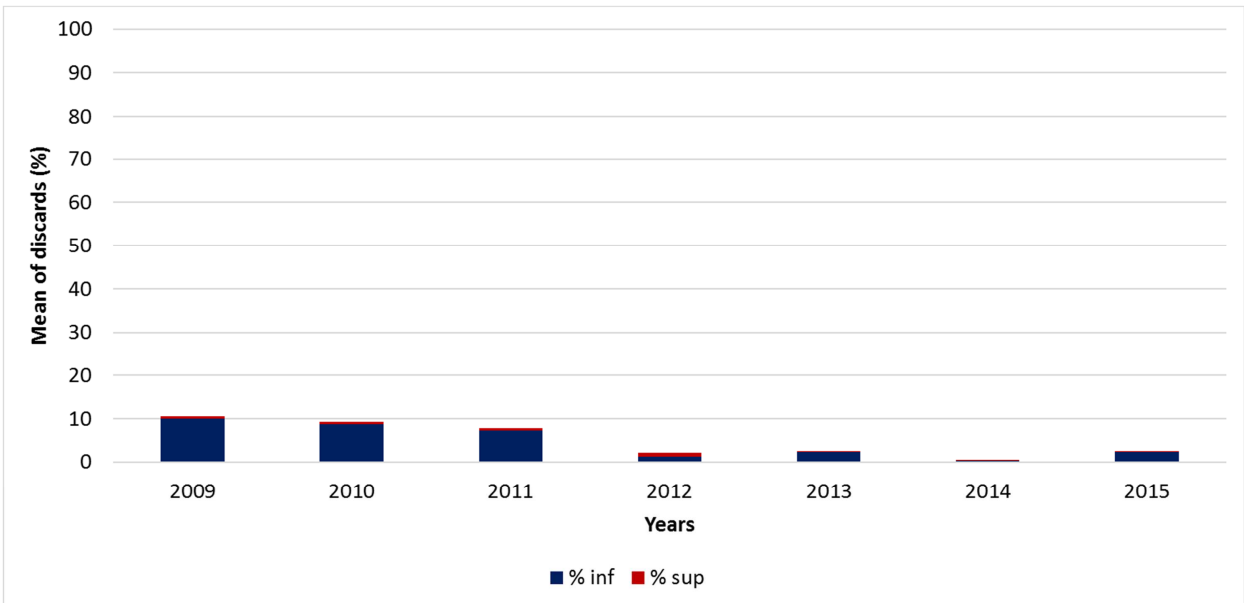

757 Figure D.3. Discard mean for all the series for OTT (2009-2015) per year in \%

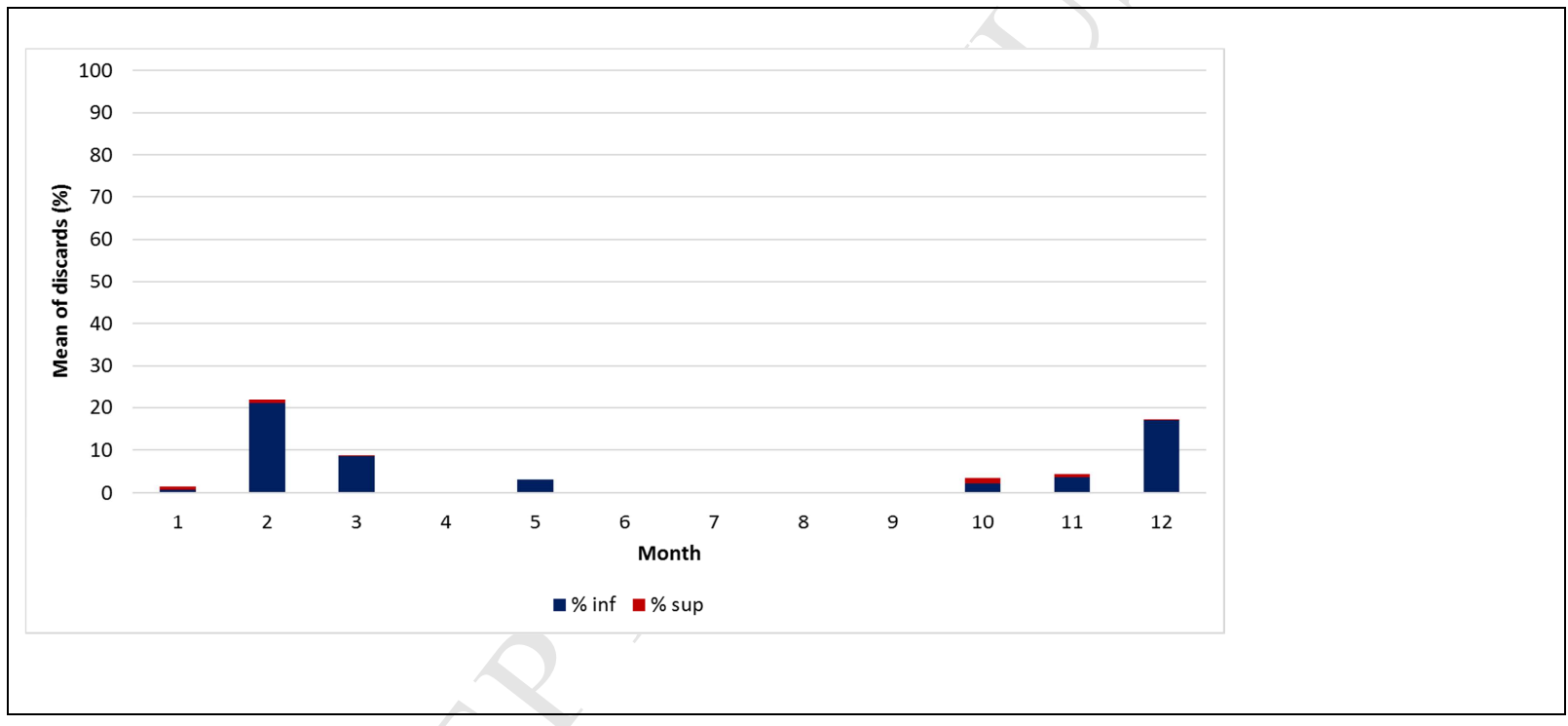




\section{ACCEPTED MANUSCRIPT}

759

760

Figure D.4. Discard mean for all the series for OTT (2009-2015) per month in \%

GNS

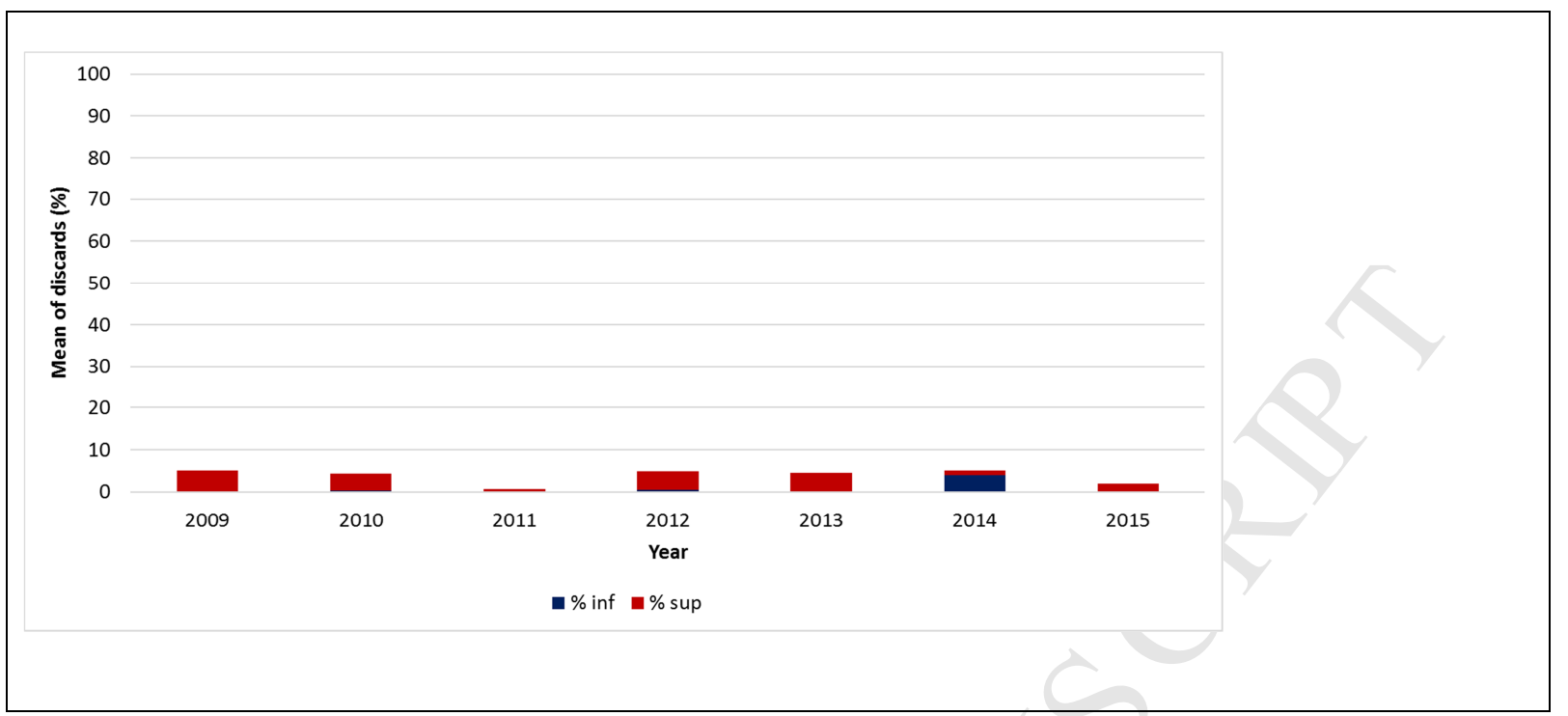

761

Figure D.5. Discard mean for all the series for GNS (2009-2015) per year in \%

762

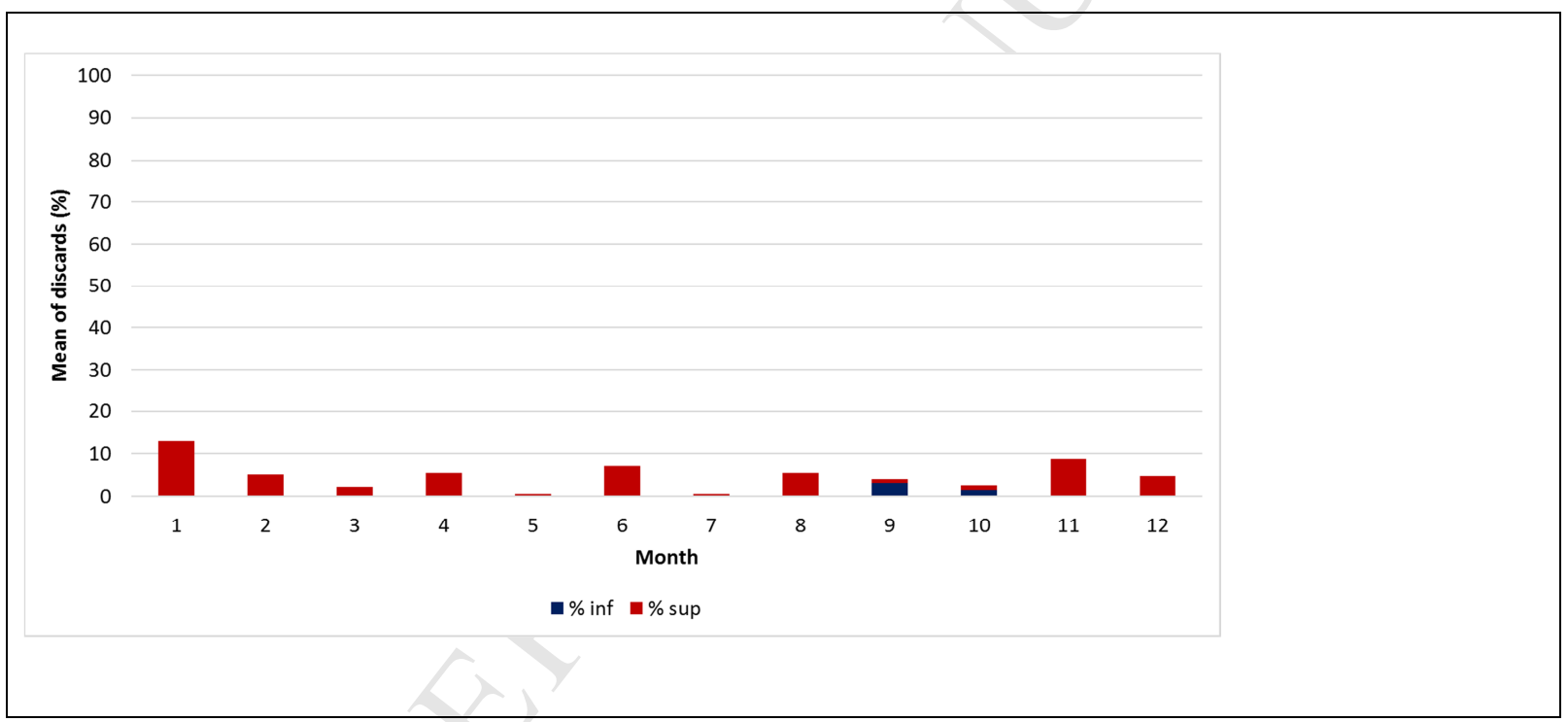




\section{ACCEPTED MANUSCRIPT}

Figure D.6. Discard mean for all the series for GNS (2009-2015) per month in \% GTR

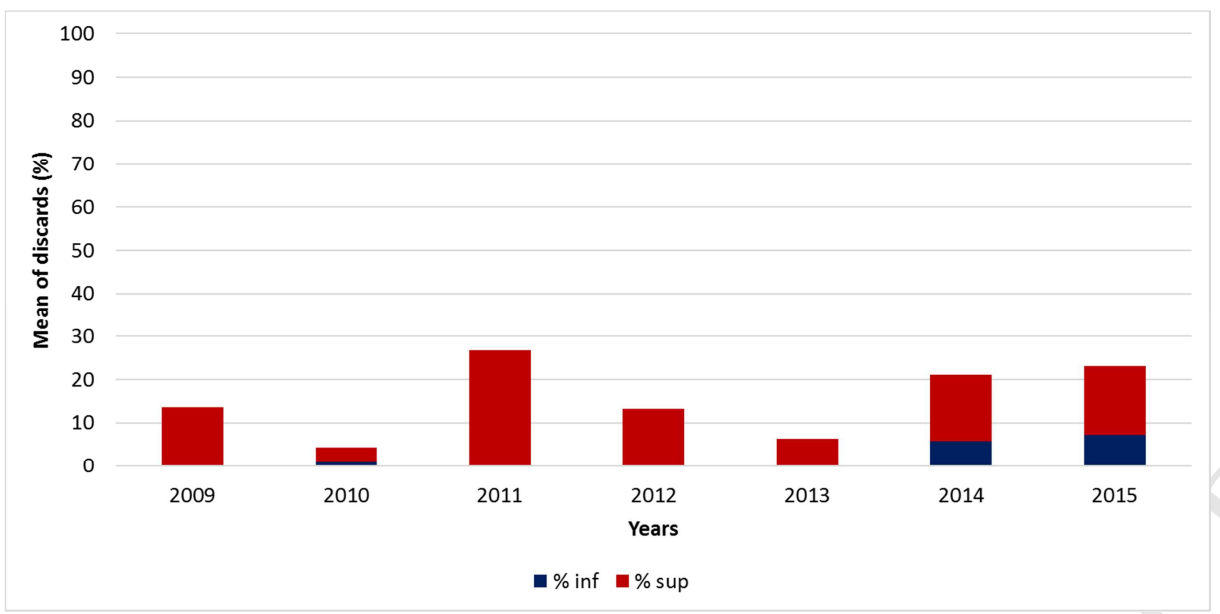

Figure D.7. Discard mean for all the series for GTR (2009-2015) per year in $\%$

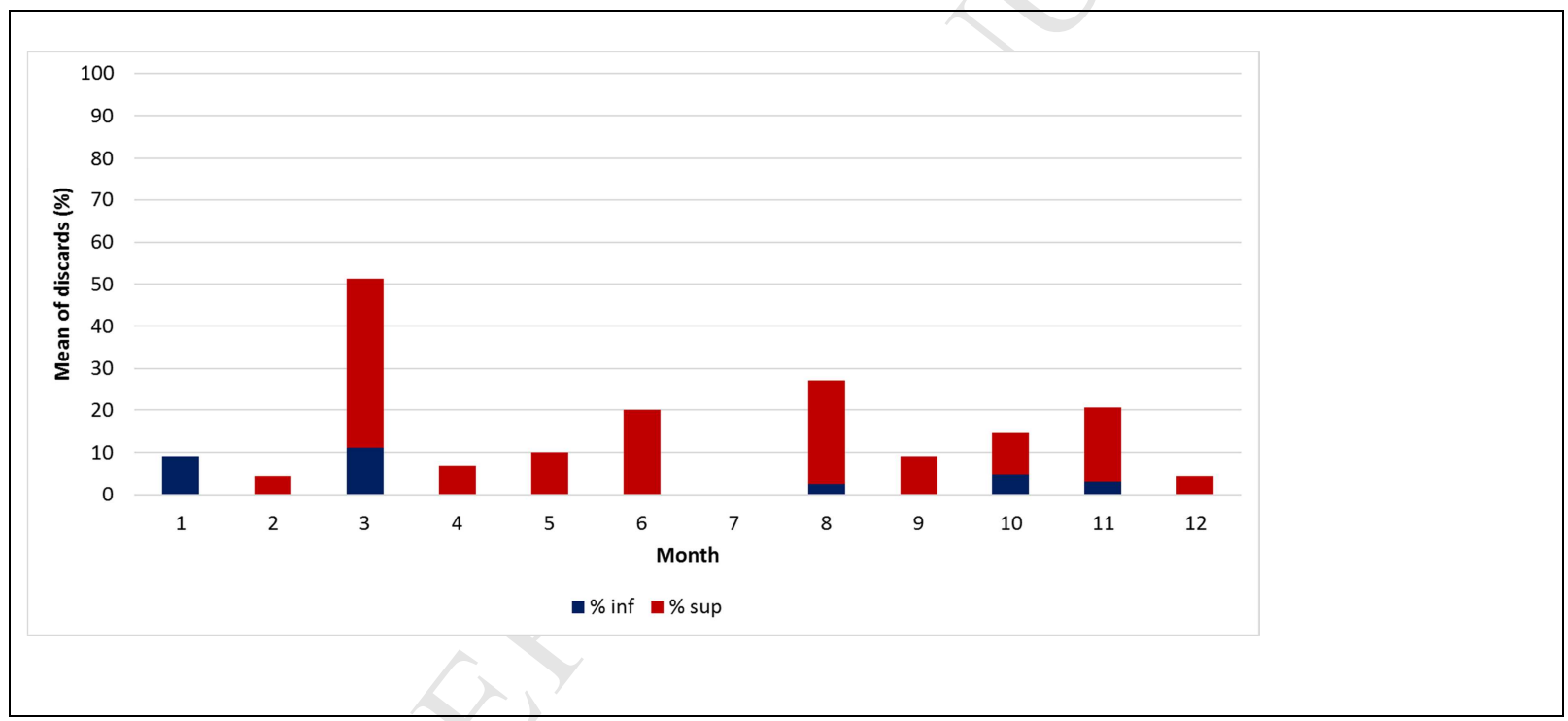




\section{ACCEPTED MANUSCRIPT}

767 Figure D.8. Discard mean for all the series for GTR (2009-2015) per month in \%

768 SDN

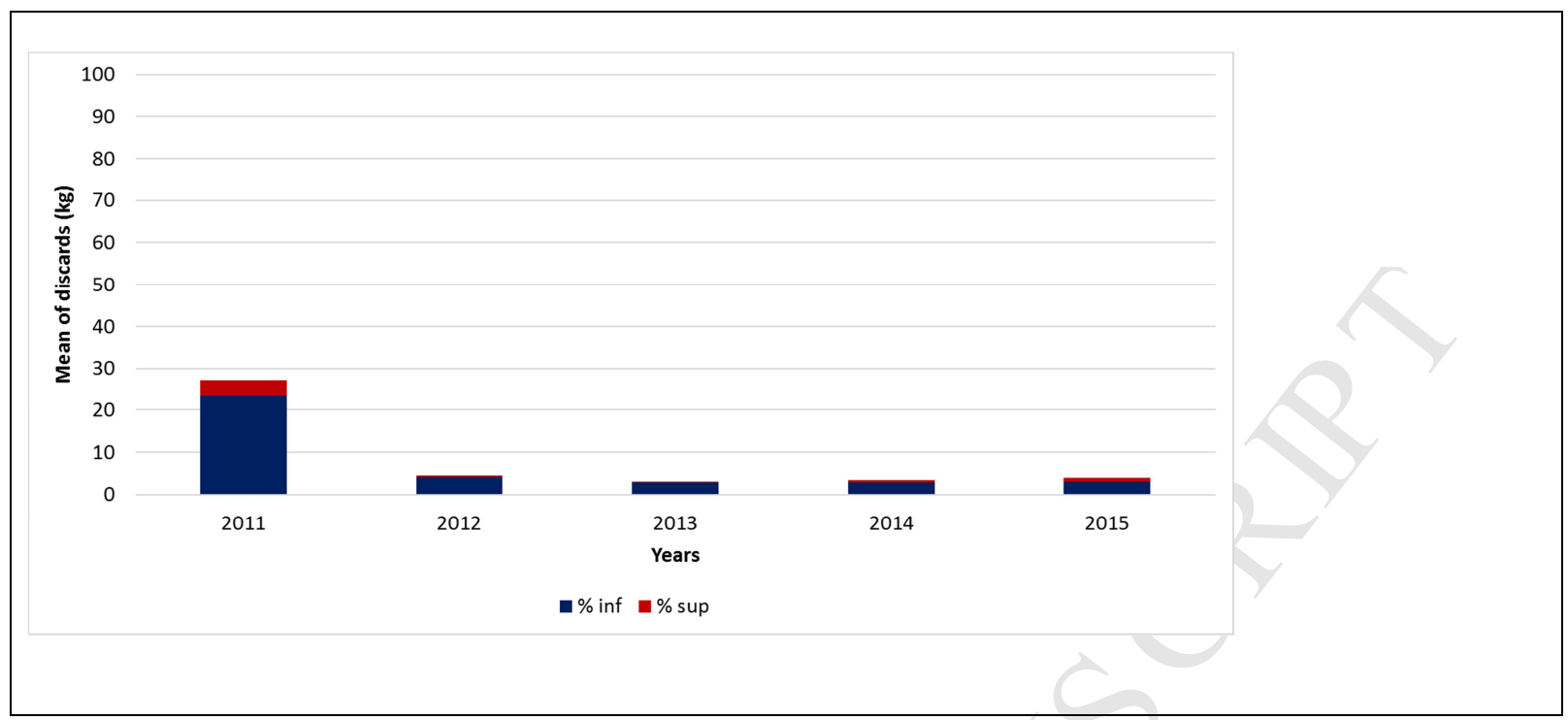

Figure D.9. Discard mean for all the series for SDN (2011-2015) per year in \%

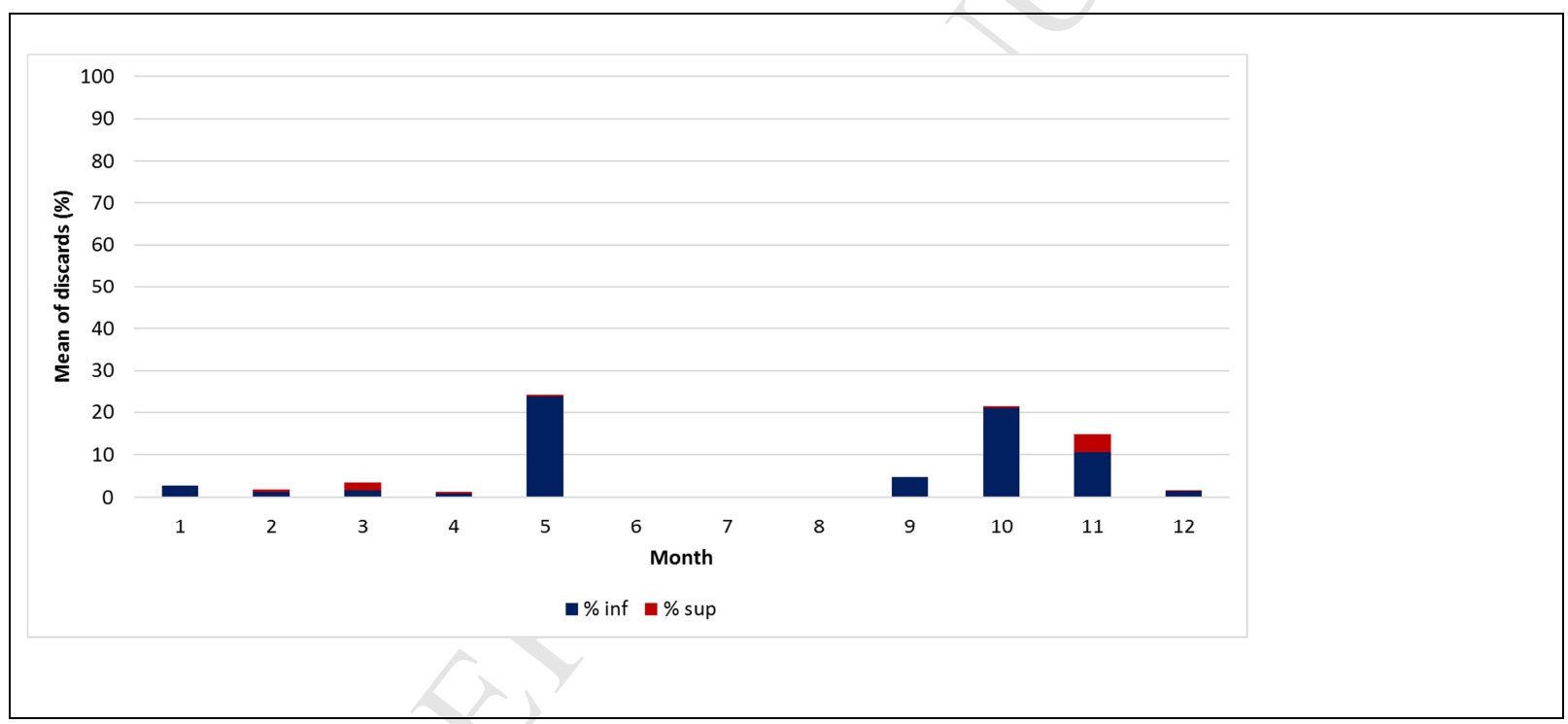

Figure D.10. Discard mean for all the series for SDN (2011-2015) per month in \% 


\section{Appendix E}

774

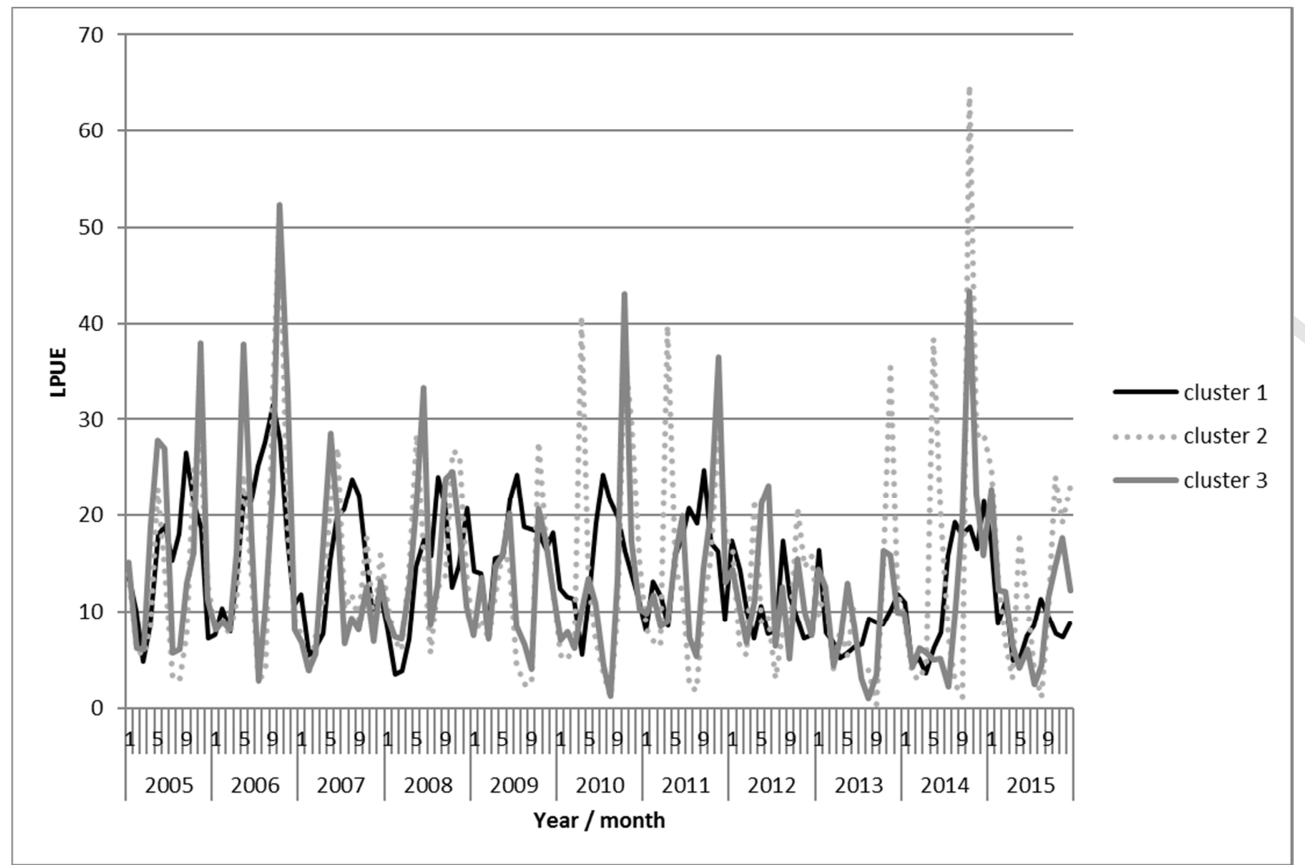

Figure E.1. Average LPUEs per cluster for Surmullet in the north of Bay of Biscay.

776

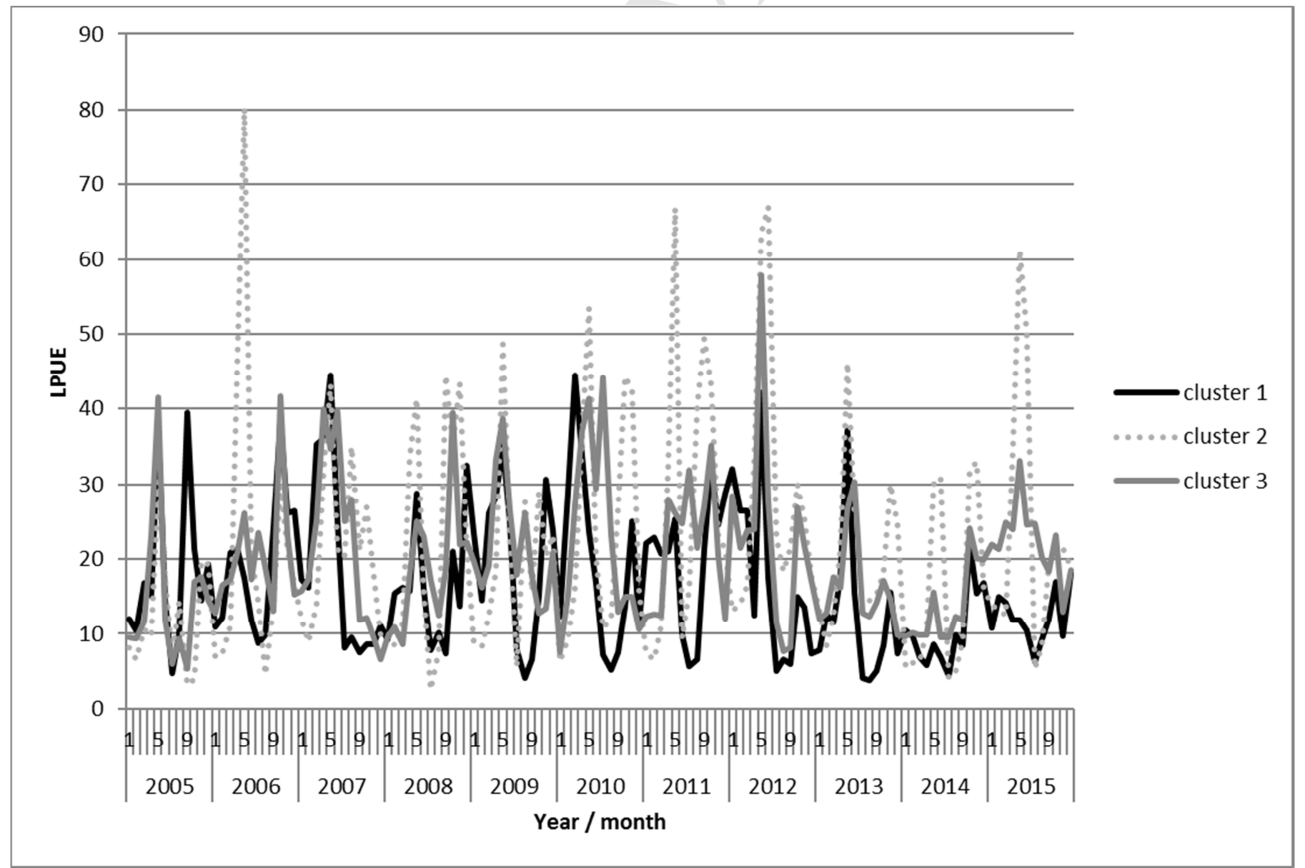

Figure E.2. Average LPUEs per cluster for Surmullet in the south of Bay of Biscay. 


\section{Appendix F}

781

$$
60
$$

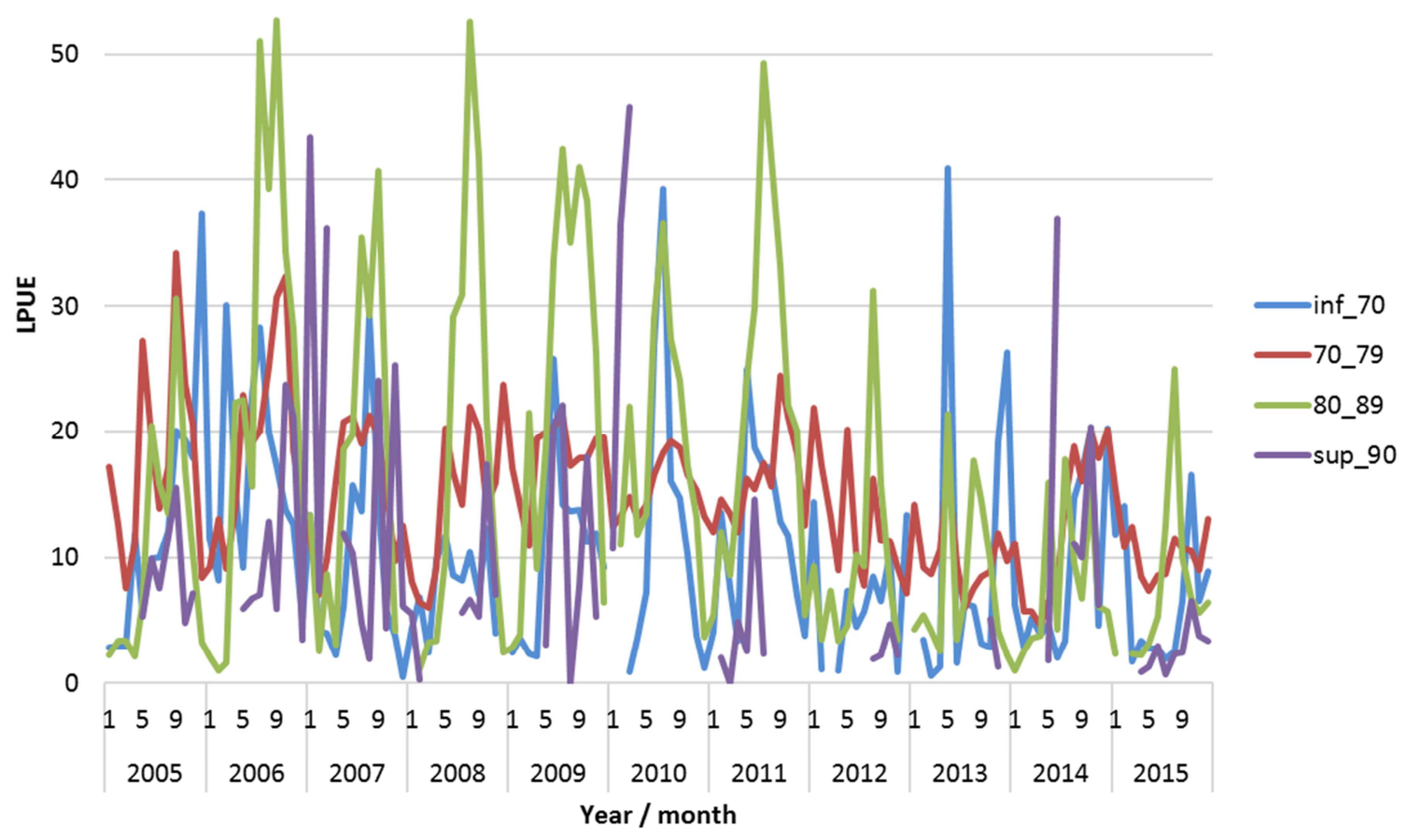

782

Figure F.1. Evolution of LPUEs mean by years and months for the different gear mesh classes for cluster 1 - OTB in the Bay of Biscay 
Appendix G

787

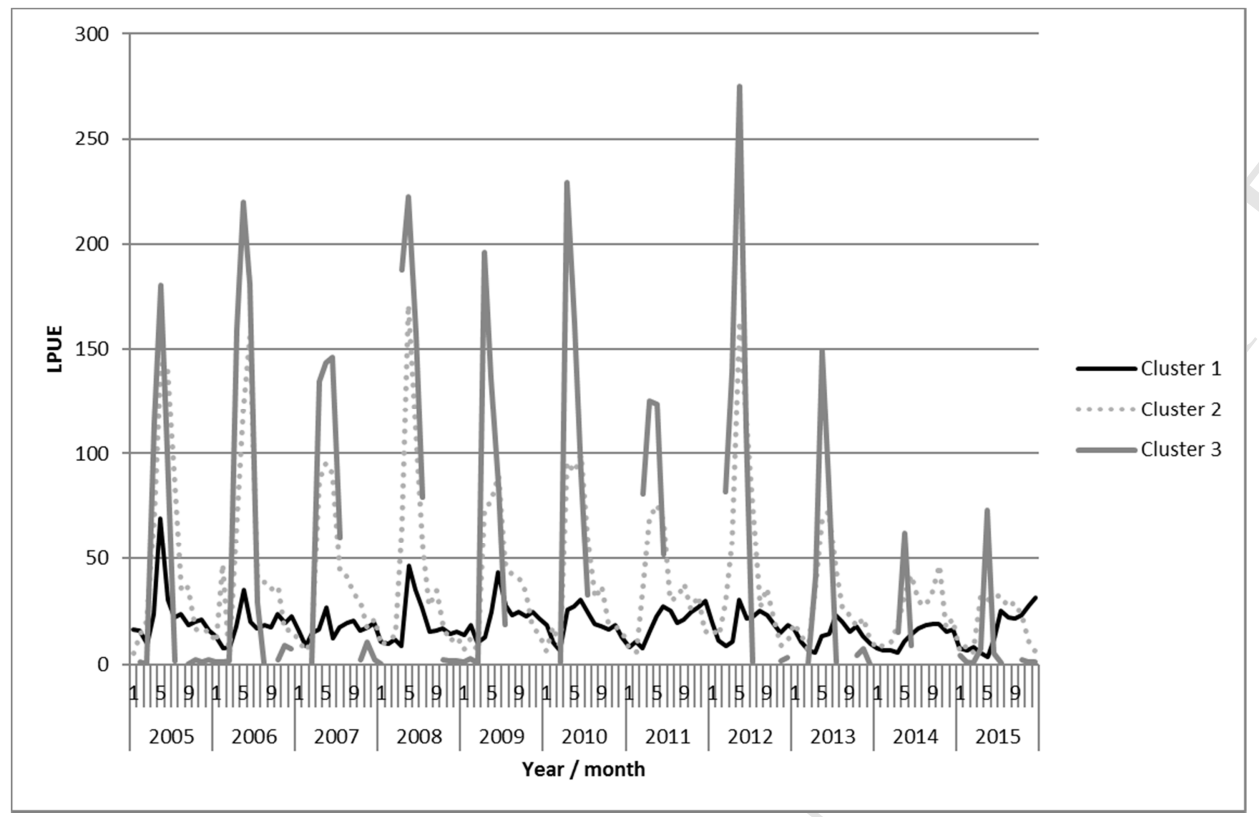

Figure G.1. Average LPUEs per cluster for Surmullet in northern Bay of Biscay.

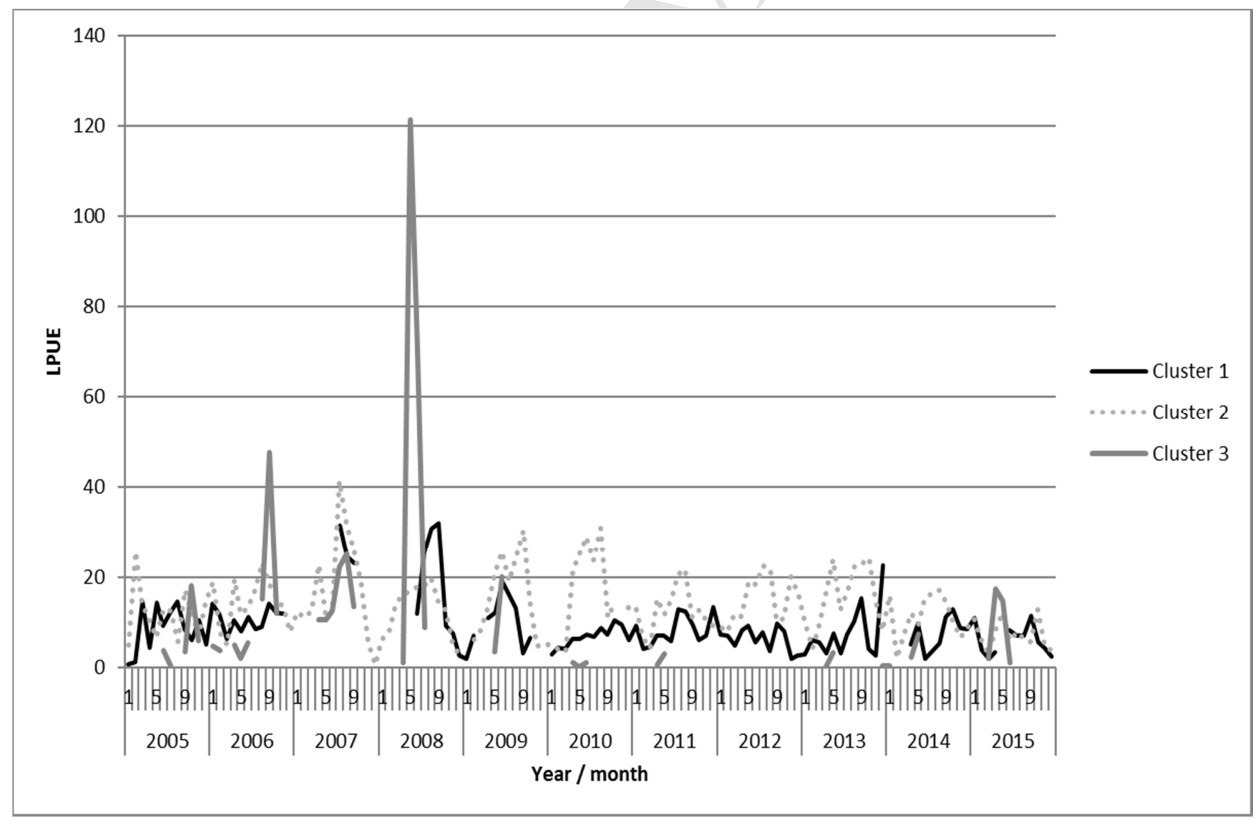

Figure G.2. Average LPUEs per cluster for Surmullet in southern Bay of Biscay. 


\section{Appendix $\mathbf{H}$}

791

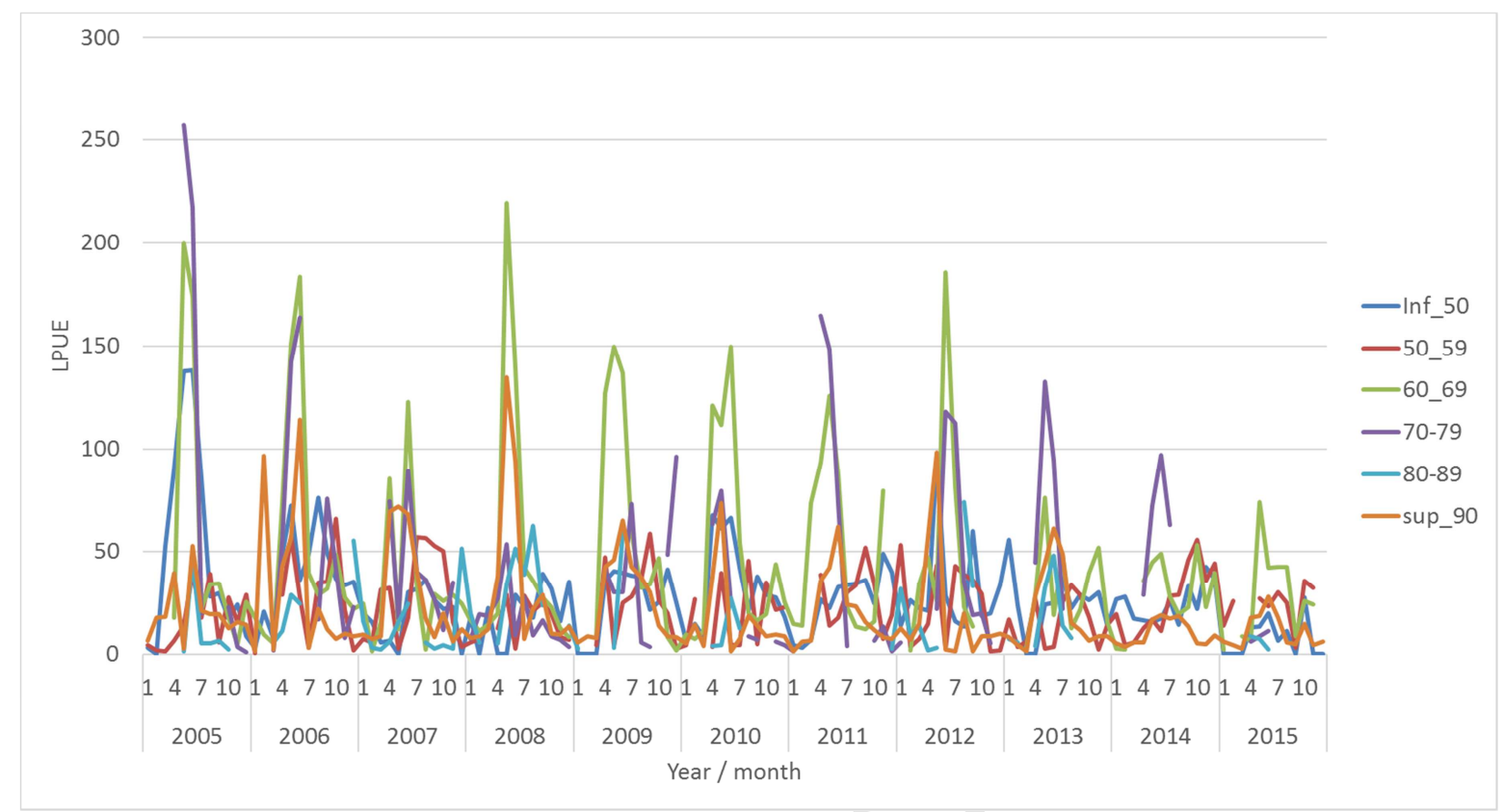

793 Figure H.1. Evolution of LPUEs mean by years and months for the different gear mesh classes for

794 cluster 2 - GNS in the Bay of Biscay 
Highlights

Data-filtering method maximizing usefulness of biological, catch, regulation data Fishermen involvement to assess impact of regulation changes on indicators Potential high bias induced by discards when using LPUE as proxy of abundance For Striped red mullet, decreasing tendency of LPUEs over the study period 